\title{
Unequivocal experimental evidence for a unified Li salt-free Wittig reaction mechanism for all phosphonium ylide types: Reactions with $\beta$-heteroatom substituted aldehydes are consistently selective for cis- oxaphosphetane derived products.
}

\author{
Peter A. Byrne and Declan G. Gilheany* \\ Centre for Synthesis and Chemical Biology, Conway Institute of Biomolecular and Biomedical Research, School of Chemis- \\ try and Chemical Biology, University College Dublin, Belfield, Dublin 4, Ireland. \\ E-mail: declan.gilheany @ucd.ie
}

\begin{abstract}
The true course of the lithium salt-free Wittig reaction has long been a contentious is sue in organic chemis try. Herein we report an experimental effect that is common to the Wittig reactions of all of the three major phos phonium ylide clas ses (non-stabilized, semi-stabilized and stabilized): there is consistently raised selectivity for cis-oxaphosphetane and its derived products (Z-alkene and erythro- $\beta$ hydroxyphosphonium salt) in reactions involving aldehydes bearing heteroatom substituents in the $\beta$-position. The effect operates with both benzaldehydes and aliphatic aldehydes and is shown not to operate in the absence of the heteroatom substituent on the aldehyde. The discovery of an effect that is common to reactions of all ylide types strongly argues for the operation of a common mechanis $m$ in all lithium salt-free Wittig reactions. In addition, the results are shown to be most easily explained by the [2+2] cycloaddition mechanis m proposed by Vedejs and co-workers as supplemented by Aggarwal, Harvey and co-workers, thus providing strong confirmatory evidence in support of that mechanism. Notably, a co-operative effect of ortho-substituents in the case of semi-stabilized ylides is confirmed and is accommodated by thecycloaddition mechanism. The effect is also shown to operate in reactions of triphenylphosphine-derived ylides, and has previously been observed for reactions under aqueous conditions, thus for the first time providing evidence that kinetic control is in operation in both of these cases.
\end{abstract}

\section{Introduction}

The Wittig reaction ${ }^{1,2,3}$ of carbonyls with phosphorus ylides is one of the most important and widely used methods for the synthes is of alkenes ${ }^{4}$ and, even now - almost 60 years after its discovery, is still being intensively studied. $5,6,7,8,9,10,11,12,13$ Concurrently, its mechanis mhas been the focus of intense and vigorous debate $^{2,3,14,15}$ and could be described as one of the great longrunning investigations of organic chemis try. Johnson ${ }^{3}$ enumerated eight different mechanistic proposals that had been advanced at various times, reflecting the tortuous path to the currently emerging consensus on the mechanis $m$. This was the result of a discontinuous uncovering of the operation of several different factors that can havea bearing on the mechanism and, especially, on the stereoselectivity of the reaction. Only in hindsight can we see that the results of valid and well-constructed studies concerned with the involvement of betaines (s alt-free or otherwise), ${ }_{16,17,18}$ and the related is sues of the effect of lithium cation $^{19,20,21,22}$ and reversible formation of intermediate $(s)^{23,24,25,26,27,28}$ led incorrectly to the twin hypotheses of the involvement of betaines and the operation of thermodynamic control in Wittig reactions. ${ }^{29}$ That these ideas persist in the modern literature ${ }^{30,31,32,33,34}$ perhaps may be attributed to their simplicity. For example, it is eas y to as sume (but ill-founded on experimental evidence) $)^{35}$ that reactions of stabilized ylides are under thermodynamic control because they are $E$-selective. Similarly, the apparent involvement of betaines as intermediates was alluring because non-Wittig reactions deliberately designed to produce betaines gave the same products as the analogous Wittig reactions. We know now that both processes produce oxaphosphetane (OPA, Scheme 1). Subsequent work has conclusively shown that solutions containing only OPA (as confirmed by NMR monitoring of the solution) give $\beta$ hydroxyphosphoniumsalt ( $\beta$-HPS) upon quenching with acid, ${ }^{36}$ and react with $\mathrm{LiBr}$ to give a betaine-LiBr complex. ${ }^{19}$ Thus there is no need to invoke the involvement of betaines in Wittig reactions. Furthermore, the non-involvement of betaines has been unequivocally demonstrated in the reaction of a particular dibenzophosphole-derived non-stabilized ylide. ${ }^{37}$ Irreversible formation of OPAs has been established for representatives of all three types of ylide, which means also that reversibility of Wittig reactions - whether they involve betaines or not - cannot be invoked to explain high $E$-selectivity. ${ }^{26,35}$ It is significant (and ironic) that the very limited number of cases in which genuine reversibility of OPA formation occurs involve non-stabilized ylides. $^{23,24,25,26}$

The present emerging consensus on the mechanis mcenters on [2+2] cycloaddition of the ylide and carbonyl to give oxaphosphetane (OPA) directly (Scheme 1). As developed by Vedejs and co-workers, ${ }^{35,38}$ and modified for reactions of stabilized ylides by Aggarwal, Harvey and co-workers, ${ }^{13}$ it is the mechanis $m$ that best accounts for experimental observations.$^{39,40}$ Consideration of this mechanism grew from the initial observation by Vedejs and Snoble ${ }^{41}$ that OPA was the only intermediate 
observable by low temperature NMR and that the high Zselectivity fromnon-stabilized alkylidenetriphenylphosphoranes could be explained by a kinetically controlled [2+2] cycloaddition of ylide and aldehyde. Subsequently the Vedejs group, ${ }^{14,15,19,26,35,38,42,43,44,45,46}$ did extensive work to establish the operation of the cycloaddition mechanism in the reactions of non-stabilized, ${ }^{26,38}$ semi-stabilized and stabilized ylides. ${ }^{35}$ Maryanoff, Reitz and co-workers ${ }^{2,20,23,24,25,47}$ and Schlosser and coworkers ${ }^{48}$ als o contributed significantly to its development. The former group of workers also identified and did extensive studies on the is sue of stereochemical drift (vide infra). More recently, the extensive kinetic studies of Mayr and co-workers confirmed that the reactivities of stabilized ylides were consistent with the cycloaddition mechanis $\mathrm{m}^{49}$

\section{Scheme 1. Present understanding of the mechanism of the} Li-salt-free Wittig reaction. ${ }^{a}$

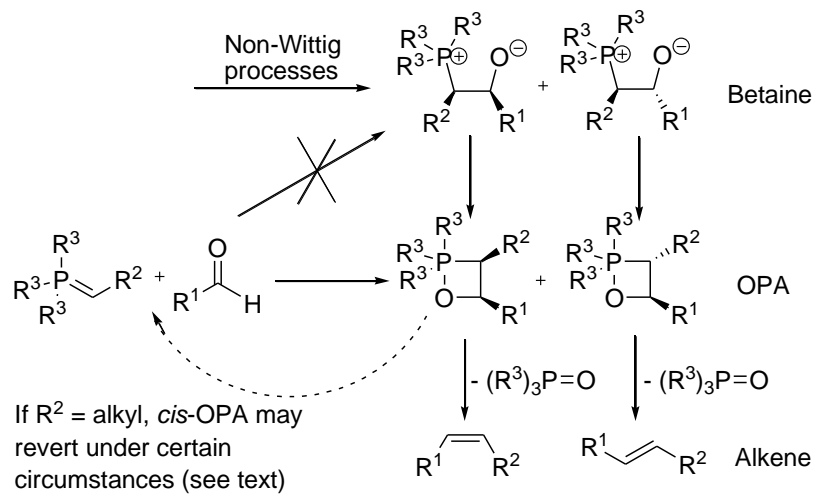

${ }^{a}$ Oxaphosphetane (OPA) formation is generally irreversible, with well-defined exceptions (all from non-stabilized ylides, see text). Betaines are not formed in the process of the salt-free Wittig reaction, but if independently generated (e.g. from $\beta$-HPS) rapidly form OPAs. Each OPA diastereomer undergoes stereospecific decomposition to alkene and phosphine oxide, perhaps after undergoing pseudorotation.

\section{Context of the present experiments:}

\section{The [2+2] cycloaddition mechanism}

We may summarize the emerging consensus as follows: it has been categorically established that salt-free non-stabilized ylides react with aldehydes by rapid and irreversible formation of $c$ is and trans-oxaphos phetane (OPA) intermediates, ${ }^{23,24,25,26,46,50,51}$ with no involvement of betaine intermediates (Scheme 1 and Figure 1(a)) prior to OPA formation. ${ }^{37}$ In a limited number of cases (discussed below), "Wittig reversal" of the cis-OPA to ylide \& aldehyde has been observed (Scheme 1), resulting in enhanced production of trans-OPA and hence $E$ alkene. ${ }^{23,24,25,26,47}$ It is als o es tablished that the OPAs (generated by non-Wittig processes) that are thought to be necess ary intermediates in the analogous Wittig reactions of semistabilized $^{35,42,52}$ and stabilized ${ }^{35,43}$ ylides do not equilibrate under the typical experimental conditions for a Wittig reaction. The presence of OPAs as intermediates has been demonstrated in the reaction of a particular dibenzophosphole-derived semistabilized ylide, ${ }^{35}$ but not, as yet, for any stabilized ylide. Reactions of stabilized ylides have been observed to be slower in acetone or DMF than in benzene ${ }^{53}$ and to have large negative activation entropy, ${ }^{53}$ which is consistent with a cycloaddition mechanism. In the reactions of all three types of ylide, the initially formed OPA (with apical carbon) undergoes facile pseu- dorotation to place the ring oxygen in an apical position in the OPA trigonal bypyramid. ${ }^{13,37,45,51}$ Finally, alkene and phosphine oxide are formed by irreversible, stereospecific syncycloreversion of the OPA. ${ }^{54,55}$ For reactions of non-stabilised ylides, the straightforward formation of OPA and substantial barrier to OPA decomposition mean that the latter is the ratedetermining step (see Fig. 1(a)). For reactions of semistabilized and stabilized ylides, the barrier to [2+2] cycloaddition is increased and that to OPA cycloreversion is significantly decreased (especially for OPAs derived from stabilized ylides) and so OPA formation is rate-determining (Fig. 1(b)). Consequently, the OPA intermediates are reasonably long-lived (at low temperature) and thus spectroscopically observable in reactions of non-s tabilized ylides, but not in those of semi-stabilized or stabilized ylides, with the exception of OPAs formed from dibenzophosphole-derived semi-stabilized ylides.

Figure 1. Reaction coordinate diagrams for Wittig reactions.
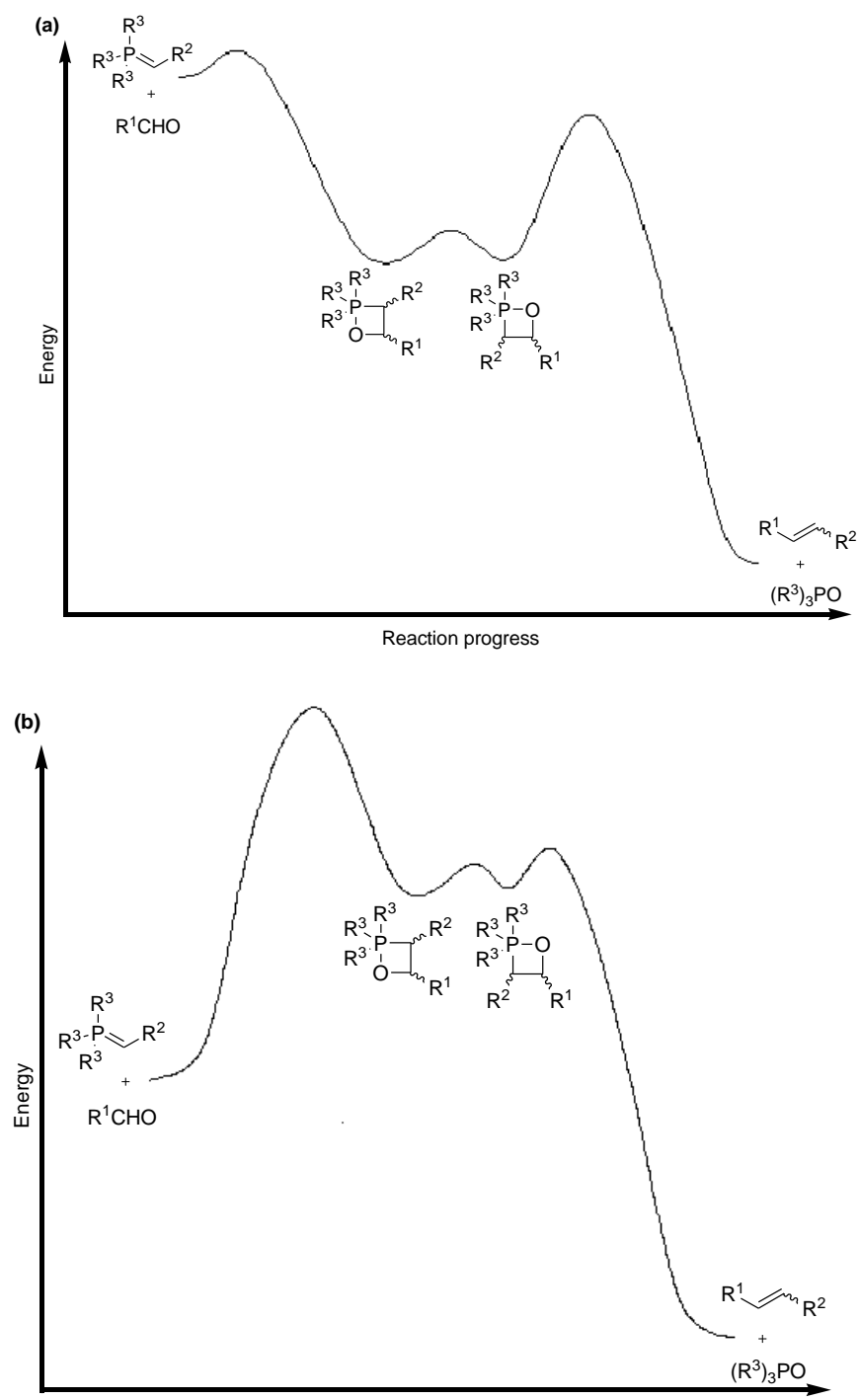

Reaction progress

(a) Reaction of a non-stabilized ylide $\left(\mathrm{R}^{3}=\mathrm{Ph}, \mathrm{R}^{2}=\right.$ alkyl), indicating rate-determining OPA decomposition.

(b) Reaction of a stabilised ylide (e.g. $\mathrm{R}^{2}=\mathrm{CO}_{2} \mathrm{Me}$ ), indicating rate determining OPA formation. 
Powerful indirect evidence supporting the [2+2] cycloaddition as a unified Wittig mechanis mis related to its use in a consistent explanation of the variation of the $Z / E$ ratios in the product alkenes ${ }^{3,14}$ It is postulated that alkylidenetriphenylphos phoranes (non-stabilized ylides) react preferentially through an early, puckered transition state in which the carbonyl substituent occupies a pseudo-equatorial position. This minimizes steric interactions between it and the $P$-phenyl groups, which are still in a pseudo-tetrahedral arrangement about phosphorus (see Fig. 2(a)). In such a transition state, the steric interactions of the ylide $\alpha$-substituent (with the $P$-phenyl groups in particular) are minimized if it is in a pseudo-axialsite, and hence this transition state leads to cis-OPA and Z-alkene. This TS simultaneously minimizes 1-2 and 1-3 interactions (see Fig. 2(a) for numbering of ring positions) for the particular arrangement of substituents about phosphorus involved, as well as allowing the forming P-O bond to avoid the $P$-phenyl group that is neces sarily projecting in the direction of the carbonyl approach to the ylide, and is thus highly favored for alkylidenetriphenylphosphoranes. ${ }^{56}$

Figure 2. Proposed [2+2] cycloaddition transition states for various Wittig reactions. (a)

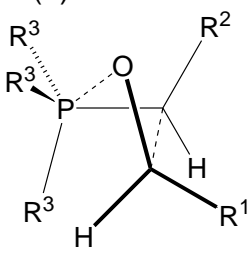

(c)

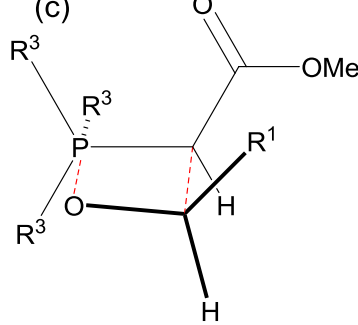

(b)

$\mathrm{R}^{3}$
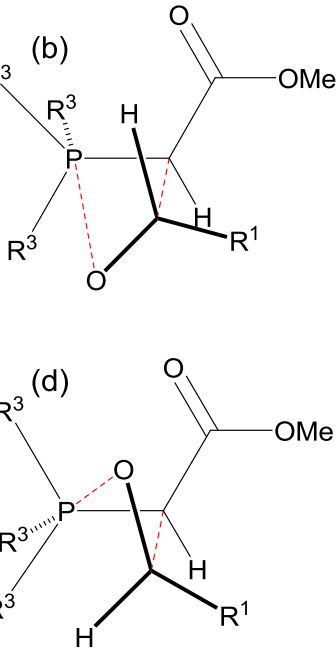

(a) Early puckered transition state with pseudo-tetrahedral arrangement of phosphorus substituents, and pseudo-trigonal planar geometry of the ylidic and carbonyl carbon substituents (for non-stabilized ylides); (b) trans-selective transition state for the reaction of a stabilized ylide, with favourable antiparallel orientation of carbonyl and $\mathrm{C}-\mathrm{CO}_{2} \mathrm{Me}$ dipoles; (c) Planar cis-selective TS for the reaction of a triphenylphosphine-derived stabilized ylide; (d) Disfavoured cis-selective TS for the reaction of a stabilized ylide, with approximately parallel orientation of carbonyl and $\mathrm{C}-\mathrm{CO}_{2} \mathrm{Me}$ dipoles.

In reactions of triphenylphosphine-derived semi-stabilized ylides, the somewhat more advanced nature of the TS, and the shape of the $\mathrm{sp}^{2}$-hybridised substituent on the ylide, results in decreased 1-3 and 2-3 steric interactions. As a consequence, a planar trans-selective TS can become competitive with a cisselective puckered TS, and poor selectivity results. In reactions of semi-stabilized ylides for which one or more of the $P$-phenyl groups are replaced by alkyl group(s), the shape of the phosphonium moiety is such that 1-3 and 2-3 interactions are further reduced, resulting in a greater preference for the planar trans- selective TS (which ensures minimal 1-2 interactions), and hence the trans-OPA and $E$-alkene.

Stabilized ylides react through a relatively late TS ${ }^{57}$ Recent calculations by Aggarwal, Harvey and coworkers indicate that the trans-selective TS (shown in Fig. 2(b)) in reactions of stabilized ylides is puckered, but importantly that this puckering is of the opposite sense to that proposed for the cis-OPA selective TS in reactions of non-stabilized ylides (Fig. 2(a)). ${ }^{13}$ This results in a TS that has an electrostatically favorable anti-parallel orientation of the carbonyl $\mathrm{C}-\mathrm{O}$ and ylide $\mathrm{C}-\mathrm{C}(\mathrm{O})$ bond dipoles. Minimization of both 1-2 and in particular 1-3 steric interactions then dictates that the large aldehyde substituent $\left(\mathrm{R}^{1}\right)$ should be pseudoequatorial, and so this TS is selective for trans-OPA. The possible (late) cis-selective TSs (planar and puckered) in these reactions of stabilized ylides (see Fig. 2 (c) and (d)) were found to be significantly higher in energy than the trans-selective TS. ${ }^{58,59}$

Confusion in the secondary/tertiary literature about the mechanism

The evidence and arguments summarized above are the bas is for the consensus among mechanis tic organophosphorus chemists on the underlying simplicity and unity of the mechanism of the salt-free Wittig reaction and how it manifests itself in practice. It can be seen however that the explanation of the source of stereoselectivity in the [2+2] cycloaddition mechanism relies on fairly complex technical arguments, with a number of caveats and exceptions to be explained. This has not helped to dispel (previously accepted) older descriptions of the mechanism involving reversible steps and/or betaine intermediates. . $31,32,33,60,61,62$ The persistence of both of these is sues may also be related to the fact that the mechanis m of the Li-salt containing Wittig reactions is still uncertain. ${ }^{33}$ Modern textbooks tend not to distinguish between Wittig reactions conducted in the presence of $\mathrm{Li}^{+}$, for which the mechanism is essentially unknown, and those that occur under Li salt-free conditions, for which the mechanis $m$ is now well-established.

In the present study, for the first time, we demonstrate an effect that is common to Li salt-free Wittig reactions of all three classes of phosphonium ylide. This is powerful confirmatory evidence that there is a unitary mechanis $m$ in operation in all kinetically controlled Wittig reactions. In addition we shall demonstrate that our results are entirely consistent with the $[2+2]$ cycloaddition mechanism. We hope that the unmasking of an unexpected effect that is common to all ylide types and which is easily explicable by the cycloaddition mechanis m will enable clarity on the mechanis m of the Li-salt free Wittig reaction for non-experts in organophosphorus mechanism.

\section{Preliminary remarks on the evaluation of kinetic diasteros e- lectivity in Wittig reactions}

There are many variables that may affect the mechanism of the Wittig reaction and thus the observed diastereomeric ratio of the alkene product. An understanding of these variables has come about through the substantial body of work carried out by Vedejs \& co-workers, Maryanoff, Reitz \& co-workers, Aggarwal, Harvey \& co-workers, Schlos ser \& co-workers and others. The importance of the foundations laid by these workers is such that it is only recently, in the aftermath of their work, that it has become possible to conduct meaningful experiments on the mechanis mof the Wittig reaction with sufficient confidence that 
the numerous variables at play are under control. We now briefly discuss these variables, the effect that they exert in the reaction, and how to prevent these effects giving rise to mis leading results in the context of the reaction mechanism.

\section{Operation of kinetic control}

Conditions have been established in which reactions of all three different ylide types occur under kinetic control - meaning that the OPA intermediates are formed irrevers ibly and undergo stereospecific decomposition to alkene and phosphine oxide. These conditions are now described.

In reactions of non-stabilized ylides it is possible to observe the OPA intermediates by low temperature NMR, and also to quench the OPA at low temperature with acid to give $\beta$-HPS (whose erythro/threo ratio corresponds directly to the cis/trans ratio of the OPA precurs or). Both of these techniques have been used to determine kinetic OPA cis/trans ratios, and in cases where both techniques have been used, the ratios have been in excellent agreement. ${ }^{2,36}$ Comparis on of the diastereomeric ratio of the intermediate determined by either method with the $Z / E$ ratio of the alkene product in all but a small number of exceptional circumstances (see section entitled "stereochemical drift" below) shows the ratios to be identical. ${ }^{23,24,25,26,46,50,51}$ Thus it can be inferred that these reactions occur under kinetic control.

For Li-salt free reactions of semi-stabilized and stabilized ylides, OPA intermediates are generally not sufficiently longlived to permit spectroscopic detection. ${ }^{63}$ Kinetic control has been established in these challenging cases by generating the OPA intermediates through processes independent of a Wittig reaction and proving that these OPAs do not interconvert, but instead undergo stereospecific decomposition to alkene and phosphine oxide. ${ }^{35}$ Triphenylphos phine-derived OPAs are not amenable to these routes (all of which require quaternization at phosphorus), and so methyldiphenylphosphine-derived OPAs, which are accessible by non-Wittig processes, have been employed in these experiments.

Based on the above experiments, if one carries out a Wittig reaction under conditions mimicking those for which the operation of kinetic control has been verified, a direct correspondence between the kinetic OPA cis/trans ratio and the observed alkene $Z / E$ ratio can be assumed (as long as steps have been taken to ensure that no is omerization of the alkene occurs after the reaction is complete - see the section entitled "Dependability of $Z / E$ ratios" below). The exceptional circums tances under which the kinetic OPA cis/trans ratio changes from its original value are well defined (see section on "stereochemical drift" below) and steps can be taken to evaluate the relevant ratio before it changes.

\section{Dependability of Z/E ratios}

In the present work, the kinetic selectivity of the OPA forming step in Wittig reactions of semi-stabilized and stabilized ylides is inferred from the observed $Z / E$ ratio of the alkene product. It is thus very important to be sure that the alkene $Z / E$ ratio is truly reflective of the kinetic OPA cis/trans ratio, and to be aware of possible means by which there may arise a non-correspondence between the two ratios. Changes may occur to the $Z / E$ ratio after completion of the reaction and/or during work-up or chromatographic purification of the alkene product. It is not sufficiently recognized that Z-1,2-disubstituted alkenes are quite easily converted, under a variety of conditions, to a $Z / E$ mixture and sometimes completely to the $E$-isomer. Therefore the $Z / E$ ratio resulting from the reaction is fragile and can be affected, by the presence of acids,${ }^{64}$ strong bases,${ }^{65}$ the chromatographic stationary phase used, the solvent, heat and sunlight. Both ourselves ${ }^{66}$ and Vedejs andPeterson ${ }^{14}$ have identified multiple previous literature reports where there was undoubtedly is omerization in favor of the $E$-alkene subsequent to the actual Wittig reaction. ${ }^{67}$ It may even occur simply if the reaction mixture is allowed to stand for a period. ${ }^{68} \mathrm{We}$ have taken extensive precautions ${ }^{69,70}$ and performed a substantial number of control experiments ${ }^{71}$ to ens ure that our observed $Z / E$ ratio is truly reflective of that rendered by the Wittig reaction in question.

\section{Stereochemical Drift}

This is a more mechanistically significant source of variation in stereochemistry. Under certain circumstances, the proportion of trans-OPA present in the initially formed mixture of OPA is omers (which reflects the extent to which the trans-OPA is preferred kinetically) may be augmented at the expense of the cis-OPA, ${ }^{14,25,26,47}$ leading to a different ratio of cis \& trans OPAs and therefore a $Z / E$ alkene ratio which is not reflective of the intrinsic kinetic selectivity of the [2+2] cycloaddition step. This phenomenon has been termed "stereochemical drift". ${ }^{25}$ Reactions conducted in the presence of additives such as salts that are soluble in the reaction solvent - in particular lithium cation, ${ }^{14,20}$ but also iodide anion, ${ }^{52}$ lithium halide with small amounts of alcohol, ${ }^{72}$ and benzoic acid ${ }^{64}$ have been shown to give $Z / E$ ratios that are altered with respect to reactions conducted in the absence of such additives. The effect of lithium ion is solvent dependent, with a profound effect being observed for reactions in non-polar solvents, and essentially no effect in solvents that effectively complex $\mathrm{Li}^{+} .{ }^{3,20}$ Hydroxylic solvents and high temperature have also been implicated as possible initiators of OPA equilibration in reactions of aromatic aldehydes..$^{14}$

More challenging is that, in certain reactions of non-stabilized ylides, stereochemical drift can occur in the absence of dissolved salts (Li or otherwise). This has been observed to occur for OPAs derived from trialkylphosphonium alkylides with tertiary or aromatic aldehydes, ${ }^{23,24,25,26,47}$ and for OPAs derived from ethylidenetriphenylphos phorane with benzaldehyde (although in the latter of these, stereochemical drift only occurs at or above the temperature at which OPA can decompose to alkene, while below this temperature the OPA diastereomeric ratio remains identical to the low temperature kinetic ratio). ${ }^{19} \mathrm{By}$ the use of cros sover experiments, the enhanced production of trans-OPA in these examples was shown to arise from reversal of the cis-OPA exclusively to ylide and aldehyde and subsequent recombination of these reactants. In each of the above examples, the OPAs were generated by deprotonation of $\beta$-HPS. In the course of the present study the occurrence of this phenomenon has been confirmed by comparis on of the kinetic cis/trans ratio of the OPA and the Z/E ratio of the alkene produced in the reactions of non-stabilized ylides ethylidenetriphenylphosphorane, ${ }^{73}$

$\mathrm{P}-$ (ethylidene)ethyldiphenylphosphorane, ${ }^{73}$ and P-(ethylidene)-Pphenyldibenzophospholane ${ }^{74}$ with each of benzaldehyde and 2bromobenzaldehyde. In each case, a greater proportion of the $E$-is omer was observed to be present in the alkene product than would have arisen from the trans-OPA initially generated. 


\section{Our interest in this area}

This arose some years ago, ${ }^{66}$ when we reported on a curious phenomenon in the Wittig reactions of triphenylphos phonium benzylides with ortho-substituted benzaldehydes. Strong orthoeffects from substituents on phosphorus were already well known through the work of McEwen and co-workers ${ }^{75,76}$ and these had been extended to the Wittig reaction, although with conflicting results. ${ }^{77,78}$ It was also known that $Z$-selectivity in stilbene synthesis could be induced by ortho-substituents with heteroatomlone pairs on the aldehyde ${ }^{79,80}$ However, remarkably, we found that this latter Z-selectivity could be substantially augmented by an additional ortho-substituent on the benzylide, despite the fact that such a substituent would ordinarily lead to $E$-selectivity. This counter-intuitive cooperative effect was strong enough to be preparatively useful (Z/E up to 95:5) and the resulting $Z-2,2$ '-disubstituted stilbenes have been used to good effect in synthesis by others. ${ }^{81,82}$ At the time, we rationalized the results within the cycloaddition mechanism by proposing that the increased Z-selectivity arose from the induction by the ortho-heteroatomof a lowered energy transition state (TS) in the kinetically controlled cycloaddition step leading to a lowered energy cis-OPA. However, the experimental conditions employed (aqueous, room temperature, presence of sodiums alts in solution, use of triphenylphosphine derived ylides), while very convenient, were not such that kinetic control in the Wittig reaction could be as sumed and rendered the analy sis provisional at best. We have now re-investigated comprehensively the original ortho-heteroatomphenomenon under conditions ensuring kinetic controlbut, much more significantly, we have extended it to non-stabilized and stabilized ylides, and also to aliphatic aldehydes.

\section{Standard Wittig reaction conditions used in this work}

For Wittig reactions of semi-stabilized and stabilized ylides, we adopted a standard set of conditions designed: (i) to ensure kinetic control; (ii) to avoid possible initiators of stereochemical drift and (iii) to ensure that the $Z / E$ ratio of the alkene product rendered by the reaction remains unchanged after completion of the reaction. For each reaction, the (Li salt-free) ylide was pregenerated from the parent pho sphoniumbromide or chloride salt using non-nucleophilic bases NaHMDS or KHMDS in dry aprotic solvent (THF) under an atmosphere of dry nitrogen. The ylide solution was cooled to $-78^{\circ} \mathrm{C}$, and aldehyde (verified free of carboxylic acid by ${ }^{1} \mathrm{H}$ NMR), was then added drop-wise. The operation of kinetic control in reactions of methyldiphenylphosphine-derived semi-stabilized and stabilized ylides has been unequivocally verified for just these reaction conditions, ${ }^{35}$ and so the bulk of our reactions involve such ylides. We have also carried out some reactions of triphenylphosphine-derived ylides for comparison. The inorganic salts produced in these reactions $(\mathrm{NaCl}, \mathrm{NaBr}, \mathrm{KCl}, \mathrm{KBr})$ are insoluble in $\mathrm{THF}$, and are thus out of solution and exert no effect on the reaction of ylide with aldehyde. ${ }^{83}$ For reactions of semi-stabilized ylides, the reaction mixture was allowed to warm to room temperature, while reactions of stabilized ylides were quenched at $-78^{\circ} \mathrm{C}$ by addition of $\mathrm{NH}_{4} \mathrm{Cl}$ solution to ensure that the reaction had occurred at low temperature. The $Z / E$ ratio was established based on integrations of characteristic signals in the ${ }^{1} \mathrm{H} N M R$ of the crude alkene obtained after minimal aqueous work-up and be- fore chromatographic purification (unless otherwise indicated). Thus every effort has been made to ens ure that the $Z / E$ ratios we have observed in these reactions correspond directly to the kinetic OPA cis/trans ratio produced in the Wittig reaction. For reactions of non-stabilized ylides with benzaldehydes, alkene $Z / E$ ratios are not used to infer the kinetic selectivity of OPA formation, since in principle it may be pos sible for stereochemical drift to occur

at or above the temperature at which OPA decomposition to alkene and phosphine oxide commences. We instead rely on OPA cis/trans ratios (obtained by low temperature ${ }^{1} \mathrm{H}$ and ${ }^{31} \mathrm{P}$ NMR of the Wittig reaction mixture) and $\beta$-HPS erythro/threo ratios (from low temperature acid quenching of Wittig reactions) to establish the kinetic cis/trans ratio of OPA. In all cases, as expected, ${ }^{36}$ these two methods were in agreement.

Finally we note that, in general, the OPA cis/trans ratio for a Wittig reaction must be at least as high as the observed alkene $Z / E$ ratio since OPA decomposition is stereospecific and irreversible, reflecting the fact that cis-OPAs are normally higher in energy than trans-OPAs. Therefore, as long as the cis-OPA is indeed higher in energy than the trans is omer, it can be as sumed that the reactions that are highly selective for the $Z$-alkene are under dominant or total kinetic control. ${ }^{26}$ The consequence is that it is not ordinarily possible to obtain Z-selectivity by accident or by intervention of equilibration. Therefore it is apposite that our conclusions (vide infra) are dependent on high $Z / E$ ratios, which have a high likelihood of being the "true" values.

\section{Reactions of benzaldehydes \\ Results for semi-stabilized ylides}

Salts 1a-g (and selected triphenyl analogues 2) were converted to the corresponding ylides 3a-g (and analogues $\mathbf{4}$ ) and reacted with benzaldehydes $\mathbf{5 a - i}$. The $Z / E$ ratios of the stilbene products (6-27) obtained in these reactions are shown in Tables 1 and 2. At the outset, we note that in reactions with benzald ehyde, the unsubstituted benzylide of methyldiphenylphosphine shows high $E$-selectivity (Table 1 entry 15 ), in good agreement with literature precedent, ${ }^{84}$ whereas that from triphenylphos phine is known to show s light $Z$-selectivity (Table 2 entry 8). ${ }^{84}$ Tables 1 and 2 show the following trends:

1. Reactions of unsubstituted benzylides with benzaldehydes bearing an ortho-heteroatom (lone pair bearing) substituent show very marked $Z$-selectivity (see Table 1 , entries $1-4,6$ \& 7 and Table 2, entries 1-4). This effect is observed for both benzaldehydes that are more electrophilic at the carbonyl ("reactive") than benzaldehyde its elf, and for ortho-alkoxy substituted benzaldehdyes, which are less electrophilic than benzaldehyde. The effect is less pronounced with an ortho-methylthio substituent (Table 1 entry 8). Considering their very different starting points (Table 1, entry 15 vs. Table 2, entry 8), the magnitude of the shift towards $Z$-selectivity on ortho-substitution is very much greater in the methyldiphenyl series than in the triphenyl series (Table 1 entries $1-3, \& 6$ vs. Table 2 entries $1-4) .{ }^{85}$ There appears to be a trend in the observed $Z$-selectivity depending on the identity of the aldehyde ortho-heteroatom substituent, increasing in the order $\mathrm{F}<\mathrm{O}<\mathrm{Cl}<\mathrm{Br}<\mathrm{I}$. 


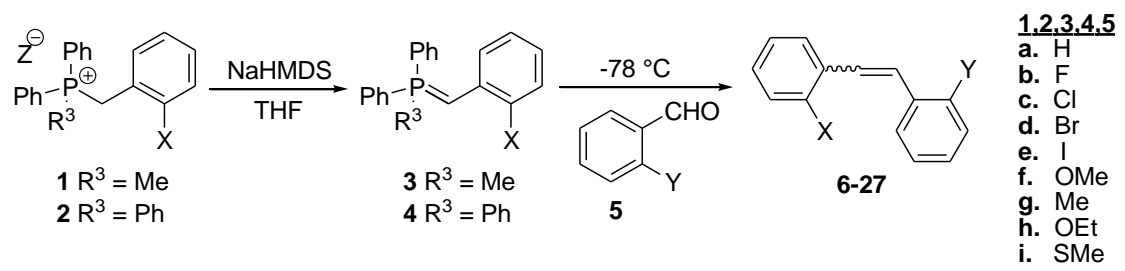

Table 1. Z/E ratio $^{a}$ for stilbenes 6-27 produced in the reactions of benzylidenemethyldiphenylphosphoranes 3a-g, derived from phos phonium salts ${ }^{b}$ 1a-g (with ortho-subs tituent X) with benzaldehydes 5 a-i (with ortho-subs tituent $Y$ ).

\begin{tabular}{|c|c|c|c|c|c|c|c|c|c|c|c|c|c|c|c|}
\hline Entry & $\begin{array}{c}\text { Ylide } \\
\text { X }\end{array}$ & $\begin{array}{c}\text { Ald } \\
\mathbf{Y}\end{array}$ & $\begin{array}{c}Z / E \\
\text { ratio }\end{array}$ & Entry & $\begin{array}{c}\text { Ylide } \\
\mathbf{X}\end{array}$ & $\begin{array}{c}\text { Ald } \\
\mathbf{Y}\end{array}$ & $\begin{array}{c}Z / E \\
\text { ratio }\end{array}$ & Entry & $\begin{array}{c}\text { Ylide } \\
\text { X }\end{array}$ & $\begin{array}{c}\text { Ald } \\
\mathbf{Y}\end{array}$ & $\begin{array}{c}Z / E \\
\text { ratio }\end{array}$ & Entry & $\begin{array}{c}\text { Ylide } \\
\mathbf{X}\end{array}$ & $\begin{array}{c}\text { Ald } \\
\mathbf{Y}\end{array}$ & $\begin{array}{c}Z / E \\
\text { ratio }\end{array}$ \\
\hline 1 & $\mathrm{H}$ & $\mathrm{Cl}$ & $92: 8$ & 9 & $\mathrm{Cl}$ & $\mathrm{H}$ & $34: 66$ & 16 & $\mathrm{Cl}$ & $\mathrm{Cl}$ & $97: 3$ & $24^{c}$ & $\mathrm{Me}$ & $\mathrm{Cl}$ & $94: 6$ \\
\hline 2 & $\mathrm{H}$ & $\mathrm{Br}$ & $94: 6$ & 10 & $\mathrm{Br}$ & $\mathrm{H}$ & $33: 67$ & 17 & $\mathrm{Br}$ & $\mathrm{Br}$ & $98: 2$ & 25 & $\mathrm{Br}$ & $\mathrm{Me}$ & $70: 30$ \\
\hline 3 & $\mathrm{H}$ & I & $96: 4$ & 11 & I & $\mathrm{H}$ & $28: 72$ & 18 & I & I & 99:1 & 26 & $\mathrm{Cl}$ & $\mathrm{Me}$ & $73: 27$ \\
\hline 4 & $\mathrm{H}$ & $\mathrm{F}$ & $84: 16$ & 12 & $\mathrm{~F}$ & $\mathrm{H}$ & $41: 59$ & $\mathbf{1 9}^{d}$ & $\mathrm{~F}$ & $\mathrm{Br}$ & $94: 6$ & 27 & $\mathrm{~F}$ & $\mathrm{Me}$ & $52: 48$ \\
\hline 5 & $\mathrm{H}$ & $\mathrm{Me}$ & $35: 65$ & $13^{c}$ & $\mathrm{Me}$ & $\mathrm{H}$ & 7:93 & $\mathbf{2 0}^{c}$ & $\mathrm{Me}$ & $\mathrm{Me}$ & $31: 69$ & $28^{c}$ & $\mathrm{OMe}$ & $\mathrm{Me}$ & $66: 34$ \\
\hline 6 & $\mathrm{H}$ & $\mathrm{OMe}$ & $86: 14$ & $14^{c}$ & $\mathrm{OMe}$ & $\mathrm{H}$ & $12: 88$ & $21^{e}$ & $\mathrm{OMe}$ & $\mathrm{OMe}$ & $44: 56$ & & & & \\
\hline 7 & $\mathrm{H}$ & OEt & $77: 23$ & & & & & 22 & $\mathrm{Br}$ & $\mathrm{OEt}$ & $92: 8$ & 29 & $\mathrm{Br}$ & $\mathrm{OMe}$ & $95: 5$ \\
\hline 8 & $\mathrm{H}$ & $\mathrm{SMe}$ & $42: 58$ & 15 & $\mathrm{H}$ & $\mathrm{H}$ & $15: 85$ & 23 & $\mathrm{Br}$ & $\mathrm{SMe}$ & $61: 39$ & 30 & $\mathrm{OMe}$ & $\mathrm{Br}$ & $72: 28$ \\
\hline
\end{tabular}

Table 2. $Z / E$ ratio $^{a}$ for stilbenes produced in the reactions of selected benzylidenetriphenylphosphoranes 4 a and $4 d-g$ derived from phosphonium salts ${ }^{b} 2$ a and $2 \mathrm{~d}-\mathrm{g}$ (with ortho-substituent $\mathrm{X}$ ) with selected benzaldehydes 5 a and $5 \mathrm{c}-\mathrm{f}$ (with orthosubstituent Y).

\begin{tabular}{|c|c|c|c|c|c|c|c|c|c|c|c|}
\hline Entry & $\begin{array}{c}\text { Ylide } \\
\text { X }\end{array}$ & $\begin{array}{c}\text { Ald } \\
\mathbf{Y}\end{array}$ & $Z / E$ ratio & Entry & Ylide X & $\begin{array}{c}\text { Ald } \\
\mathbf{Y}\end{array}$ & $Z / E$ ratio & Entry & $\begin{array}{c}\text { Ylide } \\
\text { X }\end{array}$ & $\begin{array}{c}\text { Ald } \\
\mathbf{Y}\end{array}$ & $Z / E$ ratio \\
\hline $\mathbf{1}^{f}$ & $\mathrm{H}$ & $\mathrm{Cl}$ & $90: 10$ & $5^{f}$ & $\mathrm{Cl}$ & $\mathrm{H}$ & $51: 49$ & $9^{f}$ & $\mathrm{Cl}$ & $\mathrm{Cl}$ & $94: 6$ \\
\hline 2 & $\mathrm{H}$ & $\mathrm{Br}$ & $87: 13$ & 6 & $\mathrm{Br}$ & $\mathrm{H}$ & $42: 58$ & 10 & $\mathrm{Br}$ & $\mathrm{Br}$ & $94: 6$ \\
\hline 3 & $\mathrm{H}$ & $\mathrm{OMe}$ & $90: 10$ & $7^{c}$ & $\mathrm{OMe}$ & $\mathrm{H}$ & $42: 58$ & 11 & $\mathrm{OMe}$ & $\mathrm{OMe}$ & $90: 10$ \\
\hline \multirow[t]{2}{*}{4} & $\mathrm{H}$ & I & $88: 12$ & $\mathbf{8}^{g}$ & $\mathrm{H}$ & $\mathrm{H}$ & $59: 41$ & 12 & I & I & $94: 6$ \\
\hline & & & & & & & & 13 & $\mathrm{Me}$ & $\mathrm{Cl}$ & $95: 5$ \\
\hline
\end{tabular}

${ }^{a} Z / E$ ratio determined by ${ }^{1} \mathrm{H}$ NMR analysis of the crude product obt ained after minimal aqueous work-up. See Supplementary Information for full details of the reaction, work-up, $Z / E$ analyses and characterisation of the starting materials and product alkenes.

${ }^{b}$ Counterion $\mathrm{Z}=\mathrm{Br}^{-}$in all cases except where otherwise noted.

${ }^{c}$ Counterion $\mathrm{Z}=\mathrm{Cl}^{-}$.

${ }^{d}$ The corresponding result for $\mathrm{X}=\mathrm{Br}, \mathrm{Y}=\mathrm{F}: \mathrm{Z} / E=84: 16$. The case $\mathrm{X}=\mathrm{Y}=\mathrm{F}$ is excluded because the alkene is especially prone to isomersisation.

$e^{e}$ This reaction was also carried out using the phosphonium chloride salt, and the Z/E ratio was found to be 46:54.

${ }^{f}$ Phosphonium salt used for this reaction was not dried in the standard manner and was not stored under argon; as a consequence, the yield of alkene from the Wit tig reaction was lower and the amount of phosphine oxide produced by ylide hydroly sis higher.

${ }^{g}$ From reference 14, KHMDS used to generate theylide

2. Reactions of ortho-substituted benzylides with benzaldehyde are moderately $E$-selective. This is less pronounced in the triphenylphosphine series (Table 2, entries 5/6/7) than in the methyldiphenylphosphine series (Table 1, entries 9-14) and in the latter series, ylides with electron donating groups ("reactive") give the highest $E$-selectivity (Table 1, entries 13, 14).

3. Reactions of ortho-substituted benzylides with orthoheteroatom substituted benzaldehydes show equivalent or even greater $Z$-selectivity than the corresponding reactions of the same aldehydes mentioned in point 1 . This is almost always the case for either electron withdrawing or donating substituents (Table 1, entries 16-19, 22, 24, 29 and footnote $d$; Table 2, entries 9-13 and reference 69). The only notable exceptions are the reactions of ortho-heteroatom substituted benzaldehydes with 2-methoxybenzylidenemethyldiphenylphosphorane $\mathbf{3 f}$ (Table 1 , entries $21 \& 30$ ). Once again the increase in $Z$ - selectivity in these reactions in comparis on with the reaction of the same ylide with benzaldehyde is generally much greater ${ }^{85}$ in the methyldiphenylphosphine series (Table 1, entries 16-18, 24 vs. Table 2 , entries 9, 10, 12, 13), with the exception of reactions of 3f. As with the reactions in point 1, the magnitude of the $Z$-selectivity appears to depend on the identity of the heteroatom, increasing in the order $\mathrm{F}<\mathrm{O}<\mathrm{Cl} \leq \mathrm{Br} \leq \mathrm{I}$, culminating in the particularly striking di-iodo cases (Table 1, entry 18 and Table 2, entry 12). Although the reaction of 2(methylthio)benzaldehyde (5i) with the ortho-bromo benzylide 3d does show increased $Z$-selectivity (Table 1 , entry 23 vs. entries $8 \& 10)$ the magnitude of the increase is not as great as with other aldehydes.

4. The reaction of 2-methylbenzaldehyde with the unsubstituted methyldiphenylphosphine-derived benzylide shows moderate $E$-selectivity (Table 1, entry 5), as does its reaction with 2- 
methyl substituted ylide (entry 20). Its reaction with orthoheteroatomsubstituted benzylides shows poor to moderate $Z$ selectivity (Table 1 entries 25-28). That high $Z$-selectivity is not observed in these reactions shows that the unusual effects observed in the reactions of ortho-heteroatomsubstituted benzaldehydes is dependent on the ortho-substituent being lonepair bearing - i.e. the effect is not of steric origin

In summary, lone-pair bearing ortho-substituents on benzaldehyde result in significantly enhanced $Z$-selectivity with benzylides. There is also a counter-intuitive secondary effect whereby this Z-selectivity is increased by ortho-substituents on the benzylide.

The reactions in Table 1 have been carried out under conditions for which irreversible OPA formation has been verified in reactions of semi-stabilized ylides, ${ }^{35}$ and many of them show very high $Z$-selectivity. Consequently, we are confident that kinetic control is in operation in these reactions. ${ }^{26}$ Table 2 shows that the same magnitudes and trends in $Z / E$ ratios are obtained in the analogous reactions of benzylidenetriphenylphosphoranes, including the unusual ortho-heteroatom effects. This continuity of unexpected effects is strong evidence that the triphenyl cases too are under kinetic control. Furthermore, the trends in the results shown in Table 2, again including the signature ortho-effects are entirely consistent with those obtained in our previous report ${ }^{66}$ except that the observed $Z$-selectivities are in general higher here. This, again, is evidence that kinetic control persists even under the aqueous bi-phasic conditions that we previously used. The effect persists even when non-dry phosphonium salt is used (Table 2 entries 1, 5 and 9), so the THF solvent is wet to some degree due to water of crystallization in the phosphonium salt. In these reactions of non-dry phosphonium salts, a significant amount of phosphine oxide is produced by ylide hydrolysis and, cons equently, the yield of alkene is lower. Thus the anhydrous conditions we adopted for the purposes of ensuring kinetic control also improve the preparative utility of the reactions.

The high $Z$ selectivity in these reactions of semi-stabilized ylides points to an energy lowering of the transition state (TS) leading to the cis-oxaphosphetane (cis-OPA, see later discussion).

\section{Stabilized Ylides}

We reasoned that, if a low energy TS that is strongly selective for the cis-OPA is available to the Wittig reactions of benzylidenephosphoranes with ortho-heteroatomsubstituted benzaldehydes, there might be a similar low energy TS available to the reactions of stabilized ylides such as (alkoxycarbonylmethylidene)methyldiphenylphosphoranes 29. Reactions of such ylides have previously been shown to be under kinetic control by stereospecific formation of $Z$-alkene from the erythro- $\beta$ hydroxyphosphonium salts derived from (ethoxycarbonymethylidene)methyl-diphenylphosphorane and each of several aldehydes (including benzaldehyde). ${ }^{35}$ Therefore we examined several Wittig reactions of heteroatom-substituted aldehydes with such ylides, generated in situ from the corresponding phos phonium salt $\mathbf{2 8}$, under the same conditions as were employed for the reactions of semi-stabilized ylides. The $Z / E$ ratios determined for these reactions are shown in Table 3.
Table 3. $Z / E$ ratios for reactions of selected (alkoxycarbonylmethylidene)methyldiphenylphosphoranes 29f,h,j (generated in-situ from the corresponding phosphonium salts 28) with selected benzaldehydes 5 to give enoates $30-42{ }^{a}$

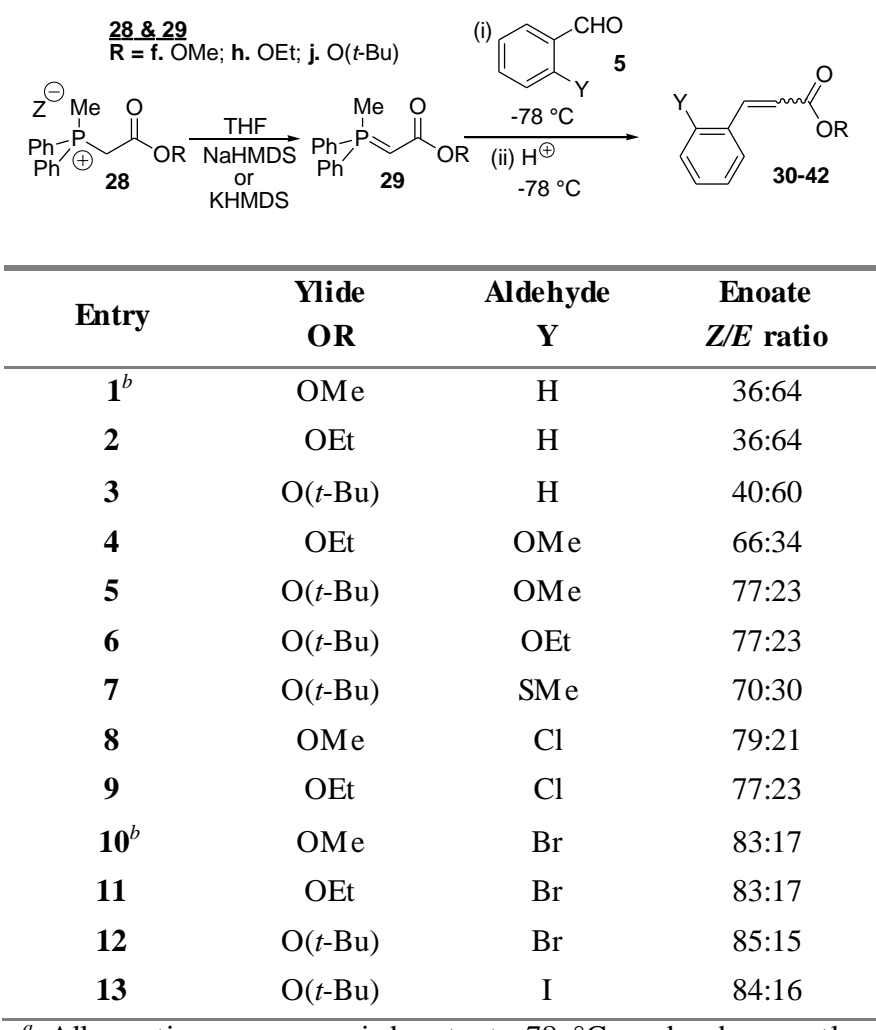

${ }^{a}$ All reactions were carried out at $-78{ }^{\circ} \mathrm{C}$, and subsequently quenched with aqueous ammonium chloride at this temperature. $Z / E$ ratio determined by ${ }^{1} \mathrm{H}$ NMR analy sis of the crude product obtained after aqueous work-up of the reaction mixture - see Supplementary Information for full details. Phosphonium salt counter-ion $\mathrm{Z}=\mathrm{Br}$ unless otherwise indicated.

${ }^{b}$ Phosphonium salt counter-ion $\mathrm{Z}=\mathrm{Cl}^{-}$.

The $Z / E$ ratio for the reaction of ester stabilized ylide (ethoxycarbonylmethylidene)triphenylphos phorane ${ }^{86}$ with benzaldehyde in THF at $20{ }^{\circ} \mathrm{C}$ has previously been found to be 23:77. ${ }^{14,35}$ The reactions of benzaldehyde with the (alkoxycarbonylmethylidene)methyldiphenyl-phosphoranes investigated here show slightly decreased $E$-selectivity compared to this literature example (see Table 3 entries 1-3). The reactions of the same ylides with ortho-heteroatom substituted benzaldehydes show significantly enhanced Z-selectivity, both in reactions in which the aldehyde is more reactive than benzald ehyde itself (Table 3 entries 4-6) and in those where it is less reactive than benzaldehyde (Table 3 entries 8-12), as well as in reactions of benzaldehydes of similar reactivity to benzaldehyde itself (Table 3 entries $7 \&$ 13). Such selectivity is almost unprecedented outside of alcohol solvents. ${ }^{2,14}$ As in the reactions of semi-s tabilized ylides, 2-(methylthio)benzaldehyde $\mathbf{5 i}$ s hows somewhat reduced Z-selectivity compared to other orthoheteroatom substituted benzaldehydes.

These results are entirely consistent with those observed in the reactions of the semi-stabilized ylides, with the aldehydes bearing the larger bromo and iodo-substituents showing the highest $Z$-selectivity, again strongly imply that the reactions occur under kinetic control. 
The Li-salt free reactions of alkylidenetriphenylphosphoranes with aldehydes normally show exceptionally high Zselectivity. ${ }^{14}$ Therefore it is experimentally almost impossible to demons trate unequivocally an enhancement in Z-selectivity due to the presence of an ortho-heteroatom on the benzaldehyde in such Wittig reactions. In our search for suitable candidates we settled on the ylides shown in Chart 1, which do not show intrinsically high selectivity for $c i s$-OPA in their reaction with benzaldehyde. This meant that there could be a demonstrable change in the selectivity for reactions of these ylides with an ortho-heteroatomsubstituted benzaldehyde. Although reactions of ethylidenetriphenylphos phorane (47, see Chart 1$)$ are typically highly $Z$-selective, there was still some scope for increased Z-selectivity with this particular ylide that would not be available with longer chain alkylidenetriphenylphosphoranes.

Chart 1. Non-stabilized ylides (47-50) used in this study. ${ }^{a, b}$

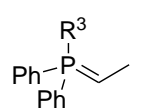

47. $R^{3}=P h$

48. $\mathrm{R}^{3}=\mathrm{Et}$

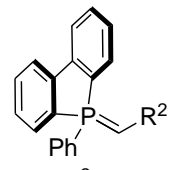

49. $R^{2}=M e$

50. $\mathrm{R}^{2}=i-\mathrm{Pr}$
${ }^{a}$ Generated in situ by treatment of the parent phosphonium bromide salts 43-46 with NaHMDS or KHMDS.

${ }^{b}$ The $P$-ethylylide 48 (rather than the $P$-methyl analogue) had to be used to avoid transylidation.

However, a complication in the context of this project was that in several instances in the reaction of ethylidenetriphenylphosphorane with benzaldehyde it has been shown that kinetic control does not operate, even under Li salt-free conditions, and so enhanced production of $E$-alkene is observed (see section on "stereochemical drift" above). ${ }^{19,25}$ Based on this, we felt that we could not infer the kinetic OPA cis/trans ratio from alkene $Z / E$ ratio with certainty in Wittig reactions of nonstabilized ylides with benzaldehydes. In order to circumvent these limitations, we decided to deal with the stereochemical drift is sue by determining the kinetic selectivity of the reactions through evaluation of low temperature OPA cis/trans ratios or erythro/threo ratios of $\beta$-HPS obtained by low temperature acid quenching of the reactions.

The erythro/threo ratio of the $\beta$-HPSs produced in the reactions of some non-stabilized ylides with benzaldehydes are shown in Table 4. The proportion of erythro- $\beta$-HPS was found to be larger in each of the reactions of ethylidenetriphenylphosphorane (47) and of (ethylidene)ethyldiphenylphosphorane (48) with 2bromobenzaldehyde (see Table 4, entries 2 and 4) than in the reactions of the same ylides with benzaldehyde (see Table 4, entries 1 and 3). However in the latter case the increase is modest best. The $Z / E$ ratios for the alkenes produced in the corres ponding unquenched Wittig reactions are also shown in Table 4 (and in Table 5 below). In certain cases, these provide evidence for the occurrence of stereochemical drift in the process of OPA decomposition (see below).
Table 4. Results of Wittig reactions of non-s tabilized ylides $47 \& 48$ with selected benzaldehydes $5 \mathrm{a}$ and $5 \mathrm{~d}$ to give OPA (initially), and subs equently $\beta$-HPS (51-54) after low temperature acid quenching of OPA. ${ }^{a}$

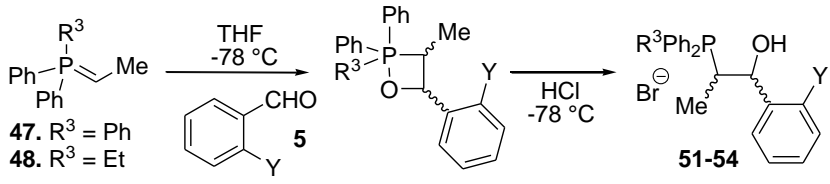

\begin{tabular}{ccccc}
\hline Entry & $\begin{array}{c}\text { Ylide } \\
\mathbf{R}^{\mathbf{3}}\end{array}$ & $\begin{array}{c}\text { Ald } \\
\mathbf{Y}\end{array}$ & $\begin{array}{c}\boldsymbol{\beta} \text {-HPS } \\
\text { erythro/threo }^{\text {ratio }^{b}}\end{array}$ & $\begin{array}{c}\text { Alkene } \\
\mathbf{Z / E} \\
\text { ratio }^{c}\end{array}$ \\
\hline $\mathbf{1}$ & $\mathrm{Ph}$ & $\mathrm{H}$ & $92: 8$ & $85: 15$ \\
$\mathbf{2}$ & $\mathrm{Ph}$ & $\mathrm{Br}$ & $97: 3^{d}$ & $79: 21$ \\
$\mathbf{3}$ & $\mathrm{Et}$ & $\mathrm{H}$ & $54: 46^{d}$ & $32: 68$ \\
$\mathbf{4}$ & $\mathrm{Et}$ & $\mathrm{Br}$ & $65: 35$ & $56: 44$ \\
\hline
\end{tabular}

${ }^{a}$ Ylides $47 \& 48$ (see Chart 1) were generated from the parent phosphonium bromide salts $\mathbf{4 3} \& \mathbf{4 4}$ respectively using NaHMDS at $20^{\circ} \mathrm{C}$. All Wittig reactions were carried out at -78 ${ }^{\circ} \mathrm{C}$, and subsequently quenched by cannulation of the reaction mixture into $\mathrm{HCl}$ solution in THF/methanol. See Supplementary Information for full details.

${ }^{b}$ The erythro/threo ratio was determined by ${ }^{1} \mathrm{H}$ and ${ }^{31} \mathrm{P}$ NMR of the crude product after minimal aqueous work-up.

${ }^{c}$ Alkene Z/E ratio from the corresponding unquenched Wittig reaction allowed to warm to room temperature after 15 minutes at $-78{ }^{\circ} \mathrm{C}$, as determined by integration of characteristic signals in the ${ }^{1} \mathrm{H}$ NMR of the crude product.

${ }^{d}$ Stereochemical assignments verified from crystal structure of the erythro-isomer. ${ }^{87}$

The reactions of phenyldibenzophosphole-derived ylides with benzaldehydes were also investigated and provided more clearcut evidence of the operation of the ortho-heteroatom effect for non-stabilized ylides. These reactions have the advantage of furnishing OPAs that are stable at room temperature (although still air sensitive), and thus it is possible to directly investigate kinetic OPA cis/trans ratios by NMR at temperatures significantly higher than $-78{ }^{\circ} \mathrm{C}$. The OPA cis/trans ratios for the reactions of benzaldehyde and 2-bromobenzaldehyde respectively with each of the ylides $P$ (ethylidene)phenyldibenzophospholane (49), $P$-(isobutylidene)phenyldibenzophospholane (50), and (ethylidene)ethyldiphenylphosphorane (48) are shown in Table 5, as are the alkene $Z / E$ ratios from the same reactions after OPA decomposition at higher temperature. The OPA cis/trans ratios were as signed by integration of characteristic signals from -60 to $-70 \mathrm{ppm}$ in the ${ }^{31} \mathrm{P}$ NMR spectrum of the reaction mixture. All the reactions investigated gave $Z$-alkene as the major product, and thus the largest OPA signal was assigned to the cisOPA in the ${ }^{31}$ PNMR spectra of the reaction mixtures, with the exception of entry 5, for which OPA diastereomers could not be resolved spectros copically.

Comparis on of Table 5 entries 2 and 4 with entries 1 and 3 again shows a distinct increase in the preference for the for- 
mation of cis-OPA in the reactions of 2-bromobenzaldehyde relative to the reactions of benzaldehyde. The diastereomeric ratio of the OPA produced in the reaction of benzaldehyde with (ethylidene)ethyldiphenylphosphorane (48) could not be determined. However, the cis/trans ratio of the OPA from the reaction of the same ylide with 2-bromobenzaldehyde matches the erythro/threo ratio of the $\beta$-HPS produced in the corres ponding low temperature acid quenching experiment using the same reactants, thus affirming conclusions drawn based on the results in Table 4.

Table 5. Results of Wittig reactions of non-s tabilized ylides 48-50 with benzaldehydes 5 a and $5 d$ to give OPAs 55-60 (initially), and subsequently alkenes 61-64. ${ }^{\circ}$

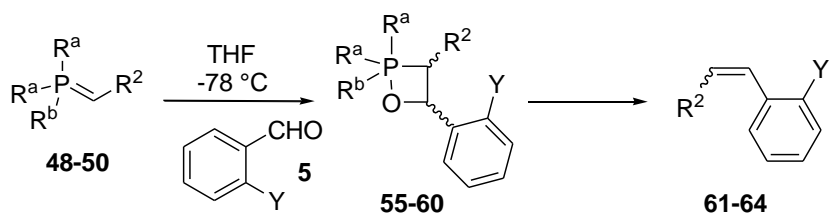

\begin{tabular}{|c|c|c|c|c|c|}
\hline \multirow{2}{*}{ Entry } & \multicolumn{2}{|c|}{ Ylide } & \multirow{2}{*}{$\begin{array}{c}\text { Ald } \\
\mathbf{Y}\end{array}$} & \multirow{2}{*}{$\begin{array}{c}\text { OPA } \\
\text { cis/trans } \\
\text { ratio }\end{array}$} & \multirow{2}{*}{$\begin{array}{c}\text { Alkene } \\
\text { Z/E } \\
\text { ratio }^{b}\end{array}$} \\
\hline & $\mathbf{R}_{2}^{\mathrm{a}} \mathbf{R}^{\mathrm{b}} \mathbf{P}$ & $\mathbf{R}^{2}$ & & & \\
\hline $\mathbf{1}^{c}$ & $\mathrm{PhDBP}^{d}$ & $\mathrm{Me}$ & $\mathrm{H}$ & $71: 29$ & $53: 47$ \\
\hline $\mathbf{2}^{c}$ & $\mathrm{PhDBP}$ & $\mathrm{Me}$ & $\mathrm{Br}$ & $94: 6$ & $82: 18$ \\
\hline $3^{e}$ & $\mathrm{PhDBP}$ & $i$-Pr & $\mathrm{H}$ & $89: 11$ & $89: 11$ \\
\hline $4^{e}$ & PhDBP & $i$-Pr & $\mathrm{Br}$ & $94: 6$ & $91: 9$ \\
\hline 5 & $\mathrm{EtPh}_{2} \mathrm{P}$ & $\mathrm{Me}$ & $\mathrm{H}$ & $-f$ & $32: 68$ \\
\hline 6 & $\mathrm{EtPh}_{2} \mathrm{P}$ & $\mathrm{Me}$ & $\mathrm{Br}$ & $64: 36^{g}$ & $56: 44$ \\
\hline
\end{tabular}

${ }^{a}$ Ylides 48-50 (see Chart 1) were generated from the parent phosphonium bromide salts 44-46 respectively using KHMDS unless otherwsie indicated. All Wittig reactions were carried out at $-78{ }^{\circ} \mathrm{C}$. OPA cis/trans ratios were determined by ${ }^{31} \mathrm{P}$ NMR after cannula filtration of the reaction mixture into an NMR tube under an inert atmosphere and addition of toluene- $d_{8}$. The ${ }^{31} \mathrm{P}$ NMR spectra all indicated the presence of small amounts of phosphine oxide by-product, which were shown to be derived from the ylide by control reactions in which no aldehyde was added, and by the fact that no alkene product could be observed by NMR prior to heating.

${ }^{b}$ Alkene $Z / E$ ratios were determined by integration of characteristic signals in the ${ }^{1} \mathrm{H}$ NMR of the crude product. DBP-derived OPAs were heated to $80{ }^{\circ} \mathrm{C}$ for 2 hours to effect alkene formation, while the $\mathrm{EtPh}_{2} \mathrm{P}$-derived OPA began to decompose to alkene and phosphine oxide at $c a .-10{ }^{\circ} \mathrm{C}$.

${ }^{c}$ The ylide was generated at $-20{ }^{\circ} \mathrm{C}$, and then stirred for 0.5 hours at $-45{ }^{\circ} \mathrm{C}$ before cooling to $-78{ }^{\circ} \mathrm{C}$ for the reaction. The OPA generated in this reaction was monitored by ${ }^{31} \mathrm{P} \mathrm{NMR}$ at $-20{ }^{\circ} \mathrm{C}$.

${ }^{d} \mathrm{PhDBP}=P$-phenyldibenzophosphole moiety of y lide.

${ }^{e}$ NaHMDS was used to generate the ylide from the parent phosphonium salt.

${ }^{f}$ OPA signals have the same ${ }^{31} \mathrm{P}$ chemical shifts at $-40{ }^{\circ} \mathrm{C}$ and $20{ }^{\circ} \mathrm{C}$, so no diastereomeric ratio could be determined.

${ }^{g}$ OPA cis/trans ratio determined at $-40{ }^{\circ} \mathrm{C}$.
Based on the low temperature acid quenching experiments detailed in Table 4 and the low temperature NMR experiments in Table 5, we conclude that the ortho-heteroatom induced effect is indeed in operation in the reactions of non-stabilized ylides.

A non-correspondence was observed between the kinetic OPA cis/trans ratios (evaluated as the $\beta$-HPS erythro/threo ratio) shown in Table 4 with the alkene $Z / E$ ratio obtained in the relevant Wittig reactions. Similar non-correspondence was also observed in the decomposition of the OPA adducts of $P$ (ethylidene)phenyldibenzophospholane (Table 5 entries 1 and 2) and of (ethylidene)ethyldiphenylphosphorane (Table 5 entry 5). This demonstrates the operation of stereochemical drift in these reactions, even under $\mathrm{Li}$-salt free conditions, in keeping with earlier observations of this phenomenon in reactions of ethylidenetriphenylphosphorane with aromatic aldehydes. ${ }^{19}$ However, no variance of the OPA cis/trans ratio was observed at temperatures well below that required to effect alkene formation, so the diastereomeric ratios of the $\beta$-HPSs and OPAs can reliably be equated to the kinetic ratios of the OPA-forming steps of the reactions. Negligible stereochemical drift was observed in the formation of alkene by heating the OPA adducts of $P$-(iso-butylidene)phenyldibenzophospholane (ylide 50, see Table 5 entries 3 and 4). It appears that the irreversibility or otherwise of OPA formation in reactions of non-stabilized ylides with benzaldehydes is heavily dependent on the structure of the non-stabilized ylide, and especially on the nature of the alkylidene moiety. There may now be sufficient evidence to suggest that the Li salt-free reactions of ethylides generally undergo stereochemical drift. The reactions of longer chain alkylidenetriphenylphosphoranes with benzaldehyde may generally be under kinetic control, although there are an insufficient number of examples to allow definitive conclusions to be made.

\section{Reactions of non-aromatic aldehydes}

The results described above are common to all three ylide classes. They are also self-consistent and, as will be shown below, can be explained by a common transition state arg ument. Therefore they indicate a common mechanism for the Wittig reaction of all ylide types. However, it could be counter-argued that the effect is solely confined to ortho-heteroatom substituted benzaldehydes and might not extend to other aldehydes. Therefore we were anxious to find other examples.

As it turns out, we did not have far to look. Enhanced Zselectivity is a known effect in Wittig reactions of aldehydes bearing a heteroatomsubstituent (typically an oxygen) on the $\beta$ carbon relative to the carbonyl group (i.e. similarly disposed relative to the carbonylas the ortho-heteroatoms in benzaldehydes) ${ }^{88}$ There are literature examples of this phenomenon (although in these, the mechanistic origin of the high Zselectivity has not been identified), most involving stabilized ylides, ${ }^{2,14,89,90}$ but there are also some examples involving a semi-stabilized ylides. ${ }^{2,88}$ In many of these examples, the carbonyl and the $\beta$-substituent of the aldehyde are substituents on a ring, and high $Z$-selectivity is observed only if the carbonyl and $\beta$-heteroatom are oriented $c i s$ with respect to each other, and it is highest in alcohol solvents. High $E$-selectivity is observed for similar aldehydes in which the carbonyl and $\beta$ heteroatom have trans relative orientation ${ }^{89,90,91,92,93}$ or if there is no $\beta$-heteroatom. ${ }^{89,90}$ 
We chose the aliphatic aldehyde, 1,2- $O$-isopropylidene-3- $O$ methyl- $\alpha$-D-xylopentodialdofuranose- $(1,4)^{94}(\mathbf{6 5}$, see Chart 2$)$ as our non-benzaldehyde test and we reacted it under our standard reaction conditions with some of the same ylides used in the reactions described above. The carbonyl group of this aldehyde is a substituent on a five-membered ring and there is a $\beta$-methoxy substituent oriented cis with respect to the carbon$y l^{88}$ High Z-selectivity is observed in the reactions of this aldehyde with both semi-stabilized ylides 3a,d and 78 (Table 6 entries 1,2 and 6) and stabilized ylides $\mathbf{2 9 f , h}, \mathbf{j}$ (Table 6 entries $3-5)$ to give alkenes 67-72. ${ }^{95}$ The reaction of benzylide 78 with a control aldehyde (66) lacking a $\beta$-heteroatom substituent showed complete $E$-selectivity.

Chart 2. Structures of aldehydes $65 \& 66$, and of ylide 78 .
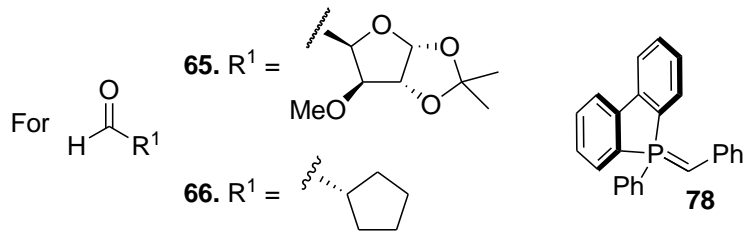

${ }^{a}$ Ylide 78 was generated in situ from the parent phos phonium bromide salt.

The reaction of aldehyde $\mathbf{6 5}$ with non-stabilized ylide $P$-(isobutylidene)- $P$-phenyldibenzophospholane (50) was also investigated, ${ }^{96}$ and ${ }^{31} \mathrm{P}$ NMR observation of the kinetic cis/trans ratio of the resulting OPA (73) at $-20{ }^{\circ} \mathrm{C}$ showed it to be $94: 6$, as corroborated by the $Z / E$ ratio of $92: 8$ observed for the alkene product (75) after heating of the OPA solution to effect OPA decomposition (Table 6 entry 8 ). To show that this selectivity is indeed out of the ordinary, the reaction of the same nonstabilized ylide with cyclopentanecarbaldehyde (66) was carried out. Observation of the cis/trans ratio of OPA 74 (by ${ }^{31} \mathrm{P}$ NMR) for this reaction showed it to be 45:55. Subsequent ${ }^{1} \mathrm{H}$ NMR observation of the $Z / E$ ratio of the alkene (76) produced by heating the OPA solution showed it to be 43:57 (Table 6 entry 9), again indicating a close correspondence between the OPA and alkene diastereomeric ratios.

Thus a very striking shift in selectivity in favor of the $Z$ alkene occurs in reactions of non-s tabilized ylides with 1,2-Ois opropylidene-3- $O$-methyl- $\alpha$-D-xylopentodialdo furanose$(1,4)(\mathbf{6 5})$ compared to a similar aliphatic aldehyde lacking a suitably oriented $\beta$-heteroatom. This non-aromatic aldehyde was shown not to undergo epimerization at the $\alpha$-carbon under our reaction conditions. Using $1 \mathrm{D}$ and $2 \mathrm{D}$ NOESY NMR, it was shown that the hydrogen that had been at the $\alpha$-carbon of the aldehyde remains $c i s$ to the $\alpha$-hydrogen in each of the $Z$ alkene products (see supporting information for details ). This is consistent with earlier reports of non-epimerization of this and other related aliphatic aldehydes in Wittig reactions carried out under similar conditions. ${ }^{89,90,91,92,93,97}$

Comparing phospholium ylides $\mathbf{5 0}$ and $\mathbf{7 8}$, it is noticeable that there is a much greater shift from $E$ to $Z$ selectivity for the semi-stabilized analogue 78 in its respective reactions with 66 and 65. Thus it shows complete $E$-selectivity in its reaction with $66,{ }^{98}$ but very high $Z$-selectivity in its reaction with 65 (albeit not quite as high as the $\mathrm{MePh}_{2} \mathrm{P}$-derived analogue), demonstrating a very dramatic shift in the energy of the cisselective TS as a consequence of the presence of the heteroatom.
Table 6. $Z / E$ ratios for Wittig reactions of aliphatic aldehydes 65 and $66^{a}$ with semi-stabilized ylides $(3 \mathrm{a}, 3 \mathrm{~d} \&$ 78), stabilized ylides (29f,h,j), and non-s tabilized ylide $50 .^{b}$

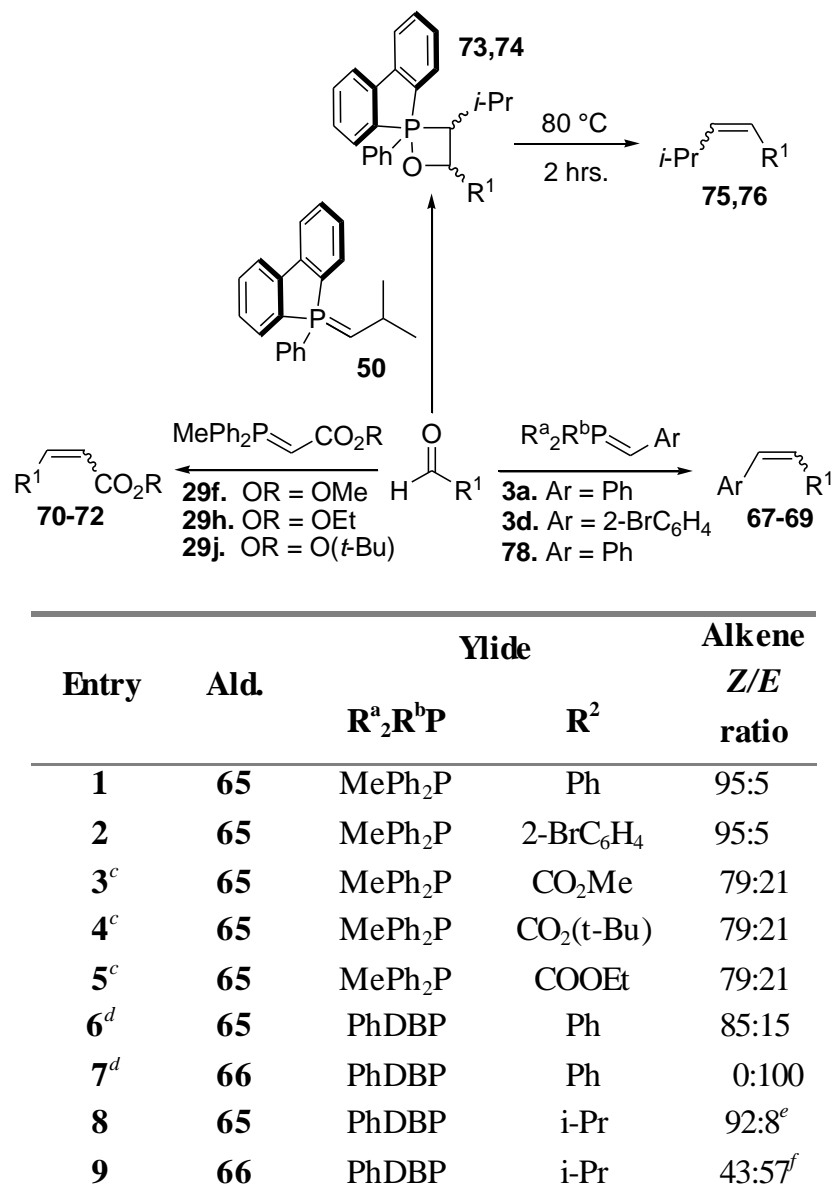

${ }^{a}$ See Chart 2 for definition of $\mathrm{R}^{1}$ in structure of $\mathbf{6 5}$ and $\mathbf{6 6}$.

${ }^{b}$ Ylides 3, 29 and $\mathbf{5 0}$ were generated from the parent phosphonium bromide salts $\mathbf{1 , 2 8}$ and $\mathbf{4 6}$ respectively using NaHMDS at $20{ }^{\circ} \mathrm{C}$. All Wittig reactions were carried out at -78 ${ }^{\circ} \mathrm{C}$. Alkene $Z / E$ ratios were determined by integration of characteristic signals in the ${ }^{1} \mathrm{H}$ NMR of the crude product.

${ }^{c}$ Reactions of stabilized ylides were quenched at $-78{ }^{\circ} \mathrm{C}$ by addition of aqueous $\mathrm{NH}_{4} \mathrm{Cl}$ in order to ensure the reaction had occurred at this temperature.

${ }^{d}$ Ylide 78 was generated from the correspoding phospholium bromide (77) at $-20{ }^{\circ} \mathrm{C}$ by addition of THF to a mixture of the salt and KHMDS.

$e^{e}$ The kinetic OPA cis/trans ratio was observed by ${ }^{31} \mathrm{P} \mathrm{NMR}$ at $20{ }^{\circ} \mathrm{C}$ and found to be $94: 6$. The OPA solution was heated to 80 ${ }^{\circ} \mathrm{C}$ for 2 hours to effect alkene formation.

$f$ The kinetic OPA cis/trans ratio was observed by ${ }^{31} \mathrm{P}$ NMR at 30 ${ }^{\circ} \mathrm{C}$ and found to be $45: 55$. The OPA solution was heated to 80 ${ }^{\circ} \mathrm{C}$ for 2 hours to effect alkene formation.

This high selectivity for $c i s$-OPA and/or Z-alkene in reactions of stabilized, semi-stabilized and non-stabilized ylides with non-aromatic aldehyde (65) is strikingly similar to the effect 
seen with benzaldehydes. Therefore we ascribe it to be a consequence of the same remote heteroatom effect.

\section{Rationalization of the effects within the cycloaddition mecha-} nism

The reactions detailed in this paper have been carried out in conditions under which OPAs derived from similar reagents to those we use have been shown not to equilibrate, ${ }^{26,35}$ therefore they can be as sumed to be under kinetic control. We rationalize the signature aldehyde $\beta$-heteroatom effect within the transition state model for the $[2+2]$ cycloaddition mechanis $\mathrm{m}^{38}$ with the single additional proposal of the existence of a stabilizing phosphorus-heteroatom bonding interacction ${ }^{66,79}$ in the cisselective cycloaddition TS (see Figure 3). This results in a 3centre-4-electron bond, with the acceptor orbital being one of the $\mathrm{P}-\mathrm{C}$ bond $\sigma^{*}$ orbitals, analogous to the (orthogonal) interaction forming the P-O bond. The proposal of such a throughspace interaction has long-time precedent in organophosphorus chemistry, having been used most notably by McEwen and coworkers in simple rationalizations of the rates of quaternization of ortho-substituted arylphosphines, ${ }^{75}$ and $\omega-N, N$ dimethylaminoalkylphosphines, ${ }^{99}$ and hydrolysis of orthosubstituted arylphos phonium salts ${ }^{76,100}$ More recently similar through-space interactions have been proposed to explain $\mathrm{O}-\mathrm{Se}$ peri-interactions in 1,8-substituted naphthalenes ${ }^{101,102}$ and anthroquinones ${ }^{103}$ and large long-range PP coupling constants in 1,8-diphosphanaphthalenes, ${ }^{104,105,106}$ a phosphorus-containing carborane, ${ }^{107}$ tetraphosphine ferrocenyl complexes ${ }^{108}$ biaryl bisphosphines ${ }^{109}$ and calix[4]arene bisphosphites..$^{110}$

The immediate consequence of the postulated phosphorusheteroatombond is that the TS is forced to be puckered in order to facilitate the exis tence of this bond (i.e. to get the heteroatom within bonding range of phosphorus). The already sterically encumbered environment around phosphorus becomes even more crowded, and the six substituents around phosphorus assume pseudo-octahedral geometry. There now exists the potential for significant increases in the steric interactions between the phosphorus substituents and the ylide $\alpha$-carbon substituent(2-3 interactions), in particular if the $\alpha$-carbon substituent is in a pseudo-axial site on the forming ring. These are minimized when the $\alpha$-carbon substituent $\mathrm{R}^{2}$ is in a pseudoequatorial site and thus points to the same side of the forming ring as the aldehyde substituent (see Fig. 3 (a) and (b)). This then is the source of the stabilization of the TS to cis-OPA. It is noteworthy that this cis-selective TS is very similar to the trans-selective TS proposed by Aggarwal, Harvey and coworkers $^{13}$ for reactions of stabilized ylides (see Fig. 2(b) above). The similarity is that the ring-puckering angle is negative meaning that the dihedral angle between the C-O and C- $\mathrm{R}^{2}$ bonds is greater than in a planar TS. This is the opposite of a cis-selective TS in a reaction of a non-stabilized ylide, so the $\mathrm{C}-\mathrm{O}$ bond is approximately anti-parallel to the ylide C- $\mathrm{R}^{2}$ bond (Fig. 3 (a)). The important difference in this case is that it is favorable for the aldehyde substituent to be close to phosphorus (i.e. in a pseudo-axial position in the forming ring) due to the phos phorus-heteroatombond. In the absence of this bond, 1-3 interactions would dictate that the aldehyde substituent would preferentially take up a pseudo-equatorial position. The geometry of the proposed TS is consistent with the fact that high $Z$ selectivity is observed even in reactions of stabilized ylides. Such a TS should benefit fromboth the phosphorus-heteroatom bond and the advantageous anti-parallel orientation of the car- bonyl C-O and ylide C-R ${ }^{2}$ bond dipoles that is normally only present in a trans-selective TS. ${ }^{13}$

Figure 3. (a) and (b) show different perspectives of the puckered cis-selective TS with phosphorus-heteroatom bonding. The ylidic substituent $\mathbf{R}^{2}$ is oriented as shown to minimize 2-3 steric interactions by avoiding the phosphorus $\mathbf{R}^{3}$ substituents. (c) A trans-selective TS with phosphorusheteroatom bonding suffers from large 2-3 steric interactions.
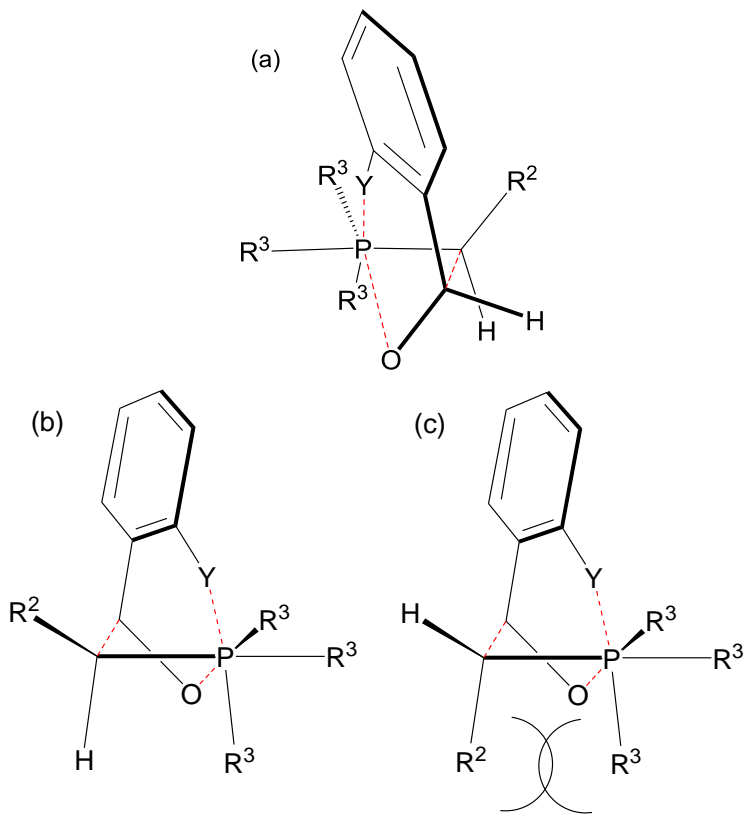

Apart from its precedence in organophosphorus chemistry, factors that argue for the existence of phosphorus -heteroatom bonding in the cycloaddition TS are: (i) the effect is observed for both aromatic and aliphatic aldehydes bearing a suitablyoriented remote heteroatom-aldehydes with no such heteroatom substituent do not show such high $Z$-selectivity; ${ }^{89,90}$ (ii) the effect is seen for benzaldehydes with both electron donating and with electron withdrawing ortho-heteroatom substituents but hardly at all with a methyl substituent; (iii) the effect increases as the heteroatom polarizability increases and electronegativity decreases - in the order $\mathrm{F}, \mathrm{OMe}, \mathrm{Cl}, \mathrm{Br}$, I (e.g. see Table 1, entries 1-4 and 6 and Table 3 entries 4-13) which would correlate with the ability of the heteroatom to bond to phosphorus - this has precedent in the reported structures of 1,8-s elenylsubstituted naphthalenes, ${ }^{101,102}$ where the magnitude of the proposed $3 \mathrm{c} 4 \mathrm{e}$ selenium-heteroatombonding interaction also appears to increase in the order $\mathrm{F}<\mathrm{Cl}<\mathrm{Br}$; (iv) related to point (iii) is the fact that cis-selectivity also increases in line with the bond length of the carbon-heteroatom bond of the aldehyde - the longer this bond and the larger and more polarizable the heteroatom, the closer the heteroatom can approach to phosphorus in the TS, thus facilitating stronger phosphorus heteroatom bonding; (v) when the heteroatoms are switched (Table 1 entry 19 and footnote $d$ ), the effect is stronger for the bromo aldehyde than the fluoro; (vi) there must be some significant effect lowering in the energy of the cis-OPA selective cycloaddition TS particularly to make Z-alkene formation predominant in the reactions of ester-stabilized ylides.

With reference to points (iii) and (iv) above, we emphasise that the strength of the phosphorus-heteroatom bond is ex- 
pected to depend on the ability of the heteroatom to be in close proximity to phosphorus, and therefore need not correlate with the (much greater) strengths of the corresponding phos phorusheteroatomsingle bonds of stable compounds. ${ }^{111}$ It is also expected to be subject to the intervention of steric effects, especially in reactions of semi-stabilised ylides where 2ethoxybenzaldehyde and 2-(methylthio)benzaldehyde show less dramatic shifts towards Z-selectivity than other orthoheteroatom substituted benzaldehydes. In these cases there als o exists the possibility of $\pi$-symmetry repulsive steric interactions between the heteroatom lone pairs or the S-Me $\sigma$ bond and the P-C $\sigma$-bonds. Another factor that could militate against phos phorus-heteroatombonding in certain circumstances is that its existence in the $c i s$-selective TS may require the conjugation between the heteroatom and the benzaldehyde ring to be broken, which would also have an as sociated energy cost.

The magnitude of the heteroatom-induced energy decrease of the $c i s$-s elective TS also appears to be affected by the degree of steric congestion about phosphorus. For reactions of semistabilised ylides the shift is greater for benzylides derived from $P$-phenyldibenzophosphole and methyldiphenylphosphine than for those derived from tripheny lphosphine. For non-stabilised ylides, the shift towards $Z$-selectivity decreases in the order $P$ phenyldibenzophosphole $>$ triphenylphosphine $>$ ethyldiphenylphosphine. Stabilised ylides derived from methyld iphenylphosphine show markedly increased $Z$-s electivity compared to those derived from triphenylphosphine. ${ }^{14,68}$

The strongest and most compelling evidence for a phosphorus-heteroatom interaction however is its ability to easily accommodate and explain the counterintuitive co-operative effect found in the semi-stabilized ylide cases. As alluded to above, Z-selectivity in reactions of benzylides with ortho-heteroatom substituted benzaldehydes is consistently higher when the benzylide also bears an ortho-substituent compared to the corresponding reaction of the unsubstituted benzylide (see Tables 1 and 2, and the as s ociated text). This can be explained as due to the cis-selective TS being better able to accommodate the increased steric demands (and es pecially 2-3 interactions) of the bulkier ylidic substituent than is the trans-selective TS, resulting in greater discrimination between the two. The high $Z$ selectivity obtained in the reactions of the ortho-heteroatom substituted benzaldehydes with the ortho-methyl substituted benzylides (Table 1 entry 24, Table 2 entry 13) shows that this is a steric effect. This subtle augmentation of the remote heteroatom effect in reactions of benzylides with benzaldehydes appears to be specific to these reactions only. It must be very dependent on the shape of the cycloaddition TSs in this particular clas s of reactions because we found no noticeable change in cis or Z-selectivity in the reactions of bulky non-stabilized or ester-stabilized ylides with heteroatom substituted aldehydes. This observation is consistent with others indicating that the energy of the cis-selective TS in reactions of semi-stabilised ylides is more sensitive to steric effects than analogous TSs in reactions of non-stabilized and stabilized ylides leading to a greater influence on selectivity from the nature of the phosphonium moiety, the ylide C-substituent and the aldehyde heteroatom substituent (if present).

Some furtherinsight into the nature of the proposed cycloaddition TS can be gleaned from the ${ }^{31} \mathrm{P}$ NMR shifts of the OPA reaction intermediate in these reactions. We looked for any evidence of phosphorus-heteroatom bonding in the OPAs derived from the non-stabilized ylides $P$ - (ethylidene)phenyldibenzophospholane (53) and $P$-(isobutylidenephenyldibenzophospholane (54) with 2bromobenzaldehyde and also with 1,2-O-isopropylidene-3-Omethyl- $\alpha$-D-xylopentodialdofuranose- $(1,4)$ for the latter ylide. These OPA intermediates have a reasonable lifetime at low temperature. We found that the ${ }^{31} \mathrm{P} N \mathrm{NMR}$ chemical shifts of all of the OPAs generated in the course of this project were in the range $\delta-60$ to $-70 \mathrm{ppm}$. An OPA with a phosphorusheteroatombond (and thus hexacoordinate phosphorus) would be expected to have a significantly more negative chemical shift in the ${ }^{31} \mathrm{P}$ NMR, analogous to oxaphosphetanides, which have previously been reported to have chemical shifts below 100 ppm. ${ }^{112,113}$ We conclude that the phosphorus in the OPA intermediates in these reactions is pentaco-ordinate. We reason that, although the phosphorus-heteroatombond could in principle be present in either a puckered or a planar TS, it seems likely that if a planar TS was capable of engaging in this stabilizing interaction, then the resulting OPA should also benefit from such stabilization. The lack of any noticeable phosphorus heteroatom interaction in the planar OPA is then consistent with the proposed puckered cis-selective TS.

\section{Conclusion}

The high Z-selectivity observed here in the Wittig reactions of heteroatomsubstituted aldehydes with all ylide types is easily explicable if all ylides react with aldehyde to form OPA by irreversible direct cycloaddition through a puckered TS. The results obtained here then, in tandem with the computational results of Aggarwal, Harvey and co-workers, corroborate the cycloaddition mechanism proposed by Vedejs and strongly support the contention that there is a common mechanism of the Wittig reaction for all ylide types and that, ordinarily, it operates under kinetic control. In particular we believe that the results for the reactions of ester-stabilized ylides with orthoheteroatom substituted benzaldehydes provide striking evidence that the reactions of stabilized ylides occur by irreversible cycloaddition of the reactants to give OPA. We hope therefore that our results will ensure that the following becomes widely known:

A: there is one mechanism of the salt-free Wittig reaction

B: it is an irreversible [2+2] cycloaddition to OPA followed by a stereospecific syn-cycloreversion to give alkene and phosphine oxide.

$\mathrm{C}$ : the stereoselectivity of all Wittig reactions is explicable by the single mechanism (especially stabilized ylide cases).

Corollaries of A-C are:

D: OPAs are the first-formed and only intermediates in Li saltfree Wittig reactions.

E: with very limited exceptions, no salt-free Wittig reaction is reversible.

Our view is that the now established Li-salt free [2+2] cycloaddition mechanismshould be presented in textbooks, and that a clear distinction should be made between this mechanism and that of Wittig reactions conducted in the presence of lithiumsalts, for which the mechanism is as yet unknown.

\section{Acknowledgements}

We thank sincerely the Irish Research Council for Science, Engineering and Technology (IRCSET) for funding this chemistry through an EMBARK Scholarship to PAB. DGG thanks sincere- 
ly University College Dublin for a President's Research Fellowship during which a substantial part of the conception of this work and initial analysis of the results took place. The Fellowship was held partly in Stanford University in the laboratory of Professor James Collman, to whom DGG is warmly appreciative for both his hospitality and stimulating intellectual discussions. We are also very grateful to UCD Centre for Synthesis and Chemical Biology (CSCB) and the UCD School of Chemistry and Chemical Biology for access to their extensive analy sis facilities and especially to Dr. Jimmy Muldoon and Dr. Yannick Ortin for NMR. Finally we thank Professor E. Vedejs, University of Michigan for helpful discussions and historical background on the Wittig reaction.
Supporting Information Available: Experimental procedures, details of the assignments of alkene $Z / E$ ratios, OPA cis/trans ratios and $\beta$-HPS erythro/threo ratios, and full characterization of all new phosphonium salts, alkenes and $\beta$-HPSs. This material is available free of charge via the Internet at http://pubs.acs.org.

\section{ABBREVIATIONS}

$\beta$-HPS, $\beta$-hydroxyphosphoniumsalt; DBP, dibenzophosphole; NOESY, nuclear Overhauser effect NMR spectroscopy; OPA, oxaphosphetane; TS, transition state.

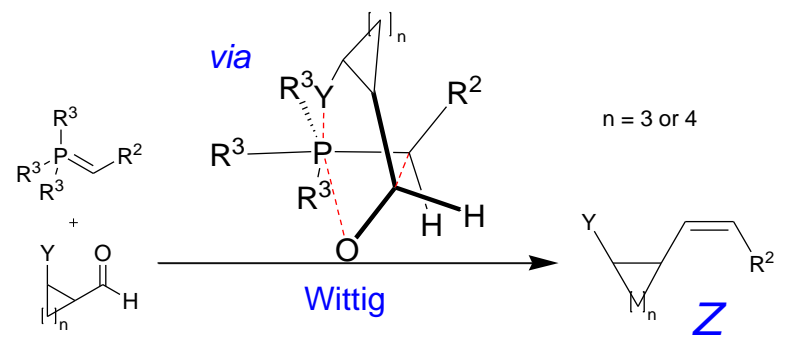

\section{REFERENCES}

1. Wittig, G.; Geissler, G. Justus Liebigs Ann. Chem. 1953, 580, 44.

2. Maryanoff, B. E.; Reitz, A. B. Chem. Rev. 1989, 89, 863.

3. Johnson, A. W. Ylides and Imines of Phosphorus, 1993, Wiley; New York, chapters 8 and 9; pp. 221-305.

4. (a) Abell, A. D.; Edmonds, M.K. in Organophosphorus Reagents; Murphy, P. J., Ed.; Oxford University Press: Oxford, U.K., 2004; pp 99-127; (b) Schobert, R. in Organophosphorus Reagents; Murphy, P. J., Ed.; Oxford University Press: Oxford, U.K., 2004; pp 12-148; (c) Edmonds, M.; Abell, A. in Modern Carbonyl Olefination; Takeda, T., Ed.; Wiley-VCH: Weinheim, Germany, 2004; Chapter 1; (d) Kolodiazhny, O. I. Phosphorus Ylides: Chemistryand Application in Organic Synthesis; Wiley: New York, 1999; (e) Gosney, I.; Rowley, A. G. in Organophosphorus Reagents in Organic Synthesis; Cadogan, J. I. G., Ed.; Academic Press, 1979; chapter 2, pp. 17-153; (f) Schlosser, M. in Topics in Stereochemistry; Eliel, E. L., Allinger, N. L., Eds.; Wiley: New York, New York, 1970, Vol. 5, pp. 1.

5. New methods forylide generation: (a) Aggarwal, V. K.; Fulton, J. R.; Sheldon, C. G.; de Vicente, J. J. Am. Chem Soc. 2003, 125, 6034; (b) Fan, R.-H.; Hou, X.-L.; Dai, L.-X. J. Org. Chem. 2004, 69, 689; (c) Lebel, H.; Pacquet, V.; Proulx, C. Angew. Chem. Int. Ed. 2001,40, 2887; (d) Ramazani, A.; Kazemizadeh, A. R.; Ahmadi, E.; Noshiranzadeh, N.; Souldozi, A. Current Organic Chemistry, 2008, 12, 59; (e) Schwartz, B. D.; Williams, C. M.; Anders, E.; Bernhardt, P. V. Tetrahedron, 2008, 64, 6482; (f) Liu, D.-N.; Tian, S. K. Chem. Eur. J. 2009, 15, 4538; (g) Zhou, R.; Wang, C.; Song, H.; He, Z. Org. Lett. 2010, 12, 976; (h) Xu, S.; Zou,W.; Wu, G.; Song, H.; He, Z. Org. Lett. 2010, 12, 3556; (i) Das, P.; McNulty, J. Eur. J. Org. Chem. $2010,3857$.

6. Methods for reactions showing atypical stereoselectivitry: (a) McNulty, J.; Keskar, K. Tetrahedron Lett. 2008, 49, 7054; (b) Oh, J. S.; Kim, B. H.; Kim, Y. G.; Tetrahedron Lett. 2004, 45, 3925; (c) Wang, Z. G.; Zhang, G. T.; Guzei, I.; Verkade, J. G.; J. Org. Chem. 2001, 61, 3521; (d) Nishimura, Y.; Shiraishi, T.; Yamaguchi, M. Tetrahedron Lett. 2008, 49, 3492; (e) Appel, M.; Blaurock, S., Berger, S. Eur. J. Org. Chem. 2002, 1143.

7. New reaction conditions: (a) El-Batta, A.; Jiang, C. C.; Zhao, W.; Anness, R.; Cooksy, A. L.; Bergdahl, M. J. Org. Chem. 2007, 72, 5244; (b) McNulty, J.; Das, P. Eur. J. Org. Chem. 2009, 4031; (c) Bera, R.; Dhananjaya, G.; Singh, S. N.; Kumar, R.; Mukkanti, K.; Pal, M. Tetrahedron 2009, 65, 1300-1305: describes the use of microwave conditions and is a good leading reference to other variations; see references $7 \mathrm{~b}, 7 \mathrm{f}$ and $7 \mathrm{~h}$ for further examples of microwave-as sis ted Wittig reactions; "on" or "in" water:(d) McNulty, J.; Das, P. Tetrahedron Lett. 2009, 50, 5737; (e) Das, P. McNulty, J.; Tetrahedron Lett. 2010, 51 , 3197; (f) McNulty, J.; Das, P.; McLeod, D. Chem. Eur. J. 2010, 16, 6756; (g) Calzavara, J.; McNulty, J. Tetrahedron Lett. 2011, 52, 5672; (h) Das, P.; McLeod, D.; McNulty, J. Tetrahedron Lett. 2011, 52, 199; (i) Tiwari, S.; Kumar, A. Chem. Commun. 2008, 4445-4447; (j) Wu, J. L.; Li, D.; Zhang, D. Synth. Comm. 2005, 2543-2551; phase-transfer conditions: (k) Pascariu, A.; Ilia. G.; Bora, A.; Iliescu, S.; Popa, A.; Dehelean, G.; Pacureanu, L. Central Eur. J. Chem. 2003, 1, 491-534; (1) 
Moussaoui, Y.; Said, K.; Ben Salem, R. ARKIVOC 2006, Part (xii), 1-22; in a ball mill: (m) Balema, V. P.; Wiench, J. W.; Pruski, M.; Pecharsky, V. K. J. Am. Chem. Soc. 2002, 124, 6244-6245; ultrasound as sisted: (n) Wu, L. Q.; Yang, C. G.; Yang, L. M.; Yang, L. J. J. Chem. Res. (S) 2009, 183-185; green Wittig reactions: (o) Nguyen, K. C.; Weizman, H. J. Chem. Ed. 2007, 84, 119-121; (p) Martin, E.; Kellen-Yuen, C. J. Chem. Ed. 2007, 84, 2004-2006.

8. One pot reactions: (a) Orsini, F.; Sello, G.; Fumagalli, T. Synlett 2006, 1717; (b) Wu, J. ; Yue, C. Synth. Commun. 2006, 36, 2939 ; (c) Choudary, B. M. ; Mahendar, K. ; Kantam, M. L. ; Ranganath, K. V. S. ; Athar, T. Adv. Synth. Catal. 2006, 348 , 1977; (d) Li, C. Y.; Zhu, B. H.; Ye, L. W.; Jing, Q.; Sun, X. L.; Tang, Y.; Shen, Q. Tetrahedron, 2007, 63, 8046; (e) Lee, E. Y.; Kim, Y.; Lee, J. S.; Park, J. Eur. J. Org. Chem. 2009, 2943. See also references 5f-h and 7a-b.

9. Synthetic studies: (a) Feist, H.; Langer, P. Synthesis, 2008, 24, 3877; (b) Okada, H.; Mori, T.; Saikawa, Y.; Nakata, M. Tetrahedron Lett. 2009, 50, 1276; (c) Wiktelius, D.; Luthman, K. Org. \& Biomol. Chem. 2007, 5, 603; (d) Molander, G. A.; Oliveira, R. A. Tetrahedron Lett. 2008, 49, 1266; (e) Rothman, J. H. J. Org. Chem., 2007, 72, 3945; (f) His ler, K.; Tripoli, R.; Murphy, J. A. Tetrahedron Lett. 2006, 47, 6293; (g) Ye, L.-W.; Han, X.; Sun, X.-L.; Tang, Y. Tetrahedron, 2008, 64, 8149. See also reference $8 d$.

10. Catalytic Wittig reaction: O’Brien, C. J.; Tellez, J. L.; Nixon, Z. S.; Kang, L. J.; Carter, A. L.; Kunkel, S. R.; Przeworski, K. C.; Chass, G. C. Angew. Chem. Int. Ed., 2009, 48, 6836. See also Fairlamb, I. J. S. ChemSusChem 2009, 2, 1021 for a review on the topic of the phosphine-catalysed Wittig reaction.

11. Wittig-type reactions of phosphoniumylides with $N$-sulfonyl imines: (a) Dong, D.-J.; Li, H. H.; Tian, S. K. J. Am. Chem. Soc. 2010, 132, 5018; (b) Dong, D.-J.; Li, Y.; Wang, J.-Q.; Tian, S. K. Chem. Commun. 2011, 47, 2158; (c) Fang, F.; Li. Y.; Tian, S. K. Eur. J. Org. Chem. 2011, 1084. Amine and $N$-sulfonyl imine-promoted Wittig reactions: (d) McNulty, J.; McLeod, D. Chem. Eur. J. 2011, 17, 8794.

12. (a) Investigation of reaction kinetics and the relative nucleophilicity of phosphoniumylides: Appel, R.; Loos, R.; Mayr, H. J. Am. Chem. Soc. 2009, 131,714; (b) Mechanistic investigation on Wittig reactions of ketones: Ghosh, A.; Chakratborty, I.; Adarsh, N. N.; Lahiri, S. Tetrahedron 2010, 66, 164; (c) Computational study on the stability of heteroatom-stabilized ylides including phosphonium ylides: Fu, Y.; Wang, H.-J.; Chong, S.-S.; Guo, Q.-X.; Liu, L. J. Org. Chem. 2009, 74, 810.

13. (a) Robiette, R.; Richardson, J.; Aggarwal, V. K.; Harvey, J. N. J. Am. Chem. Soc. 2005, 127, 13468; (b) Robiette, R.; Richardson, J.; Aggarwal V. K.; Harvey, J. N. J. Am. Chem. Soc. 2006, 128, 2394; (c) Harvey, J. N. Faraday Discuss. 2010, 145 , 487.

14. Vedejs, E.; Peterson, M. J. in Topics in Stereochemistry; Eliel, E. L., Wilen, S. H., Eds.; Wiley: New York, New York, 1994; Vol. 21, pp.1.

15. Vedejs, E.; Peterson, M. J. in Advances in Carbanion Chemistry; Snieckus, V., Ed.; JAI: Greenwich, CN, 1996; Vol. 2.

16. Schlosser, M.; Christmann, K. F. Liebigs Ann. Chem. 1967, 708, 1. Isolation of betaine-lithium halide complex from Wittig reaction.

17. Wittig, G.; Schöllkopf, U. Chem. Ber. 1954, 87, 1318. Isolation of $\beta$-HPS by acid quenching of Wittig reaction.

18. Studies involving the reaction of phosphine with epoxide to give alkene and phosphine oxide through an obligatory (Li-salt containing) betaine-intermediate: (a) Speziale, A. J.; Bissing, D. E. J. Am. Chem. Soc. 1963, 85, 3878; (b) Wittig, G.; Haag, W. Chem. Ber. 1955, 88, 1654.

19. Vedejs, E.; Meier, G. P.; Snoble, K. A. J. J. Am. Chem. Soc. 1981, 103, 2823-2831.

20. Reitz, A. B.; Nortey, S. O., Jordan Jr, A. D.; Mutter, M. S., Maryanoff, B. E. J. Org. Chem. 1986, 51, 3302.

21. Reference 14, pp. 50-54.

22. Vedejs, E., Huang, W. F. J. Org. Chem. 1984, 49, 210.

23. Maryanoff, B. E.; Reitz, A. B.; Mutter, M. S.; Inners, R. R.; Almond Jr., H. R. J. Am. Chem. Soc. 1985, 107, 1068.

24. Reitz, A. B.; Mutter, M. S.; Maryanoff, B. E. J. Am. Chem. Soc. 1984, 106, 1873.

25. Maryanoff, B. E.; Reitz, A. B.; Mutter, M. S.; Inners, R. R.; Almond Jr., H. R.; Whittle, R. R.; Olofson, R. A. J. Am. Chem. Soc. 1986, 108, 7664 .

26. Vedejs, E.; Marth, C. F.; Ruggeri, R. J. Am. Chem. Soc., 1988, 110, 3940.

27. Jones, M. E.; Trippett, S. J. Chem. Soc. (C) 1966, 1090.

28. (a) See reference 6b; (b) Anderson, R. J.; Henrick, C. A. J. Am. Chem. Soc. 1975, 97, 4327.

29. See, for example, reference $4 \mathrm{e}$.

30. See, for example, reference $4 \mathrm{c}$ pg. 3 .

31. For example reference 4a, p. 99 and p 104.

32. The is olation from Wittig reactions of non-stabilized ylides of betaine-lithiumhalide complexes ${ }^{16}$ or $\beta$-HPS ${ }^{17}$ after addition of acid, along with the fact that alkene could be generated by the reaction of epoxide with phosphine ${ }^{18}$ led, not unreasonably, to the presumption that betaines are necessarily involved as intermediates in the Wittig reaction. Z-selectivity in Wittig reactions of alkylidenetriphenylphosphoranes was proposed to arise from irreversible add ition of ylide to aldehyde to form erythrobetaine and hence cis-OPA and Z-alkene. Anti-addition of ylide to aldehyde was proposed to be the kinetically preferred route, giving anti-erythro-betaine. Bond rotation of the initially formed betaine gives syn-erythro-betaine, which cyclises to cis-OPA and hence gives Z-alkene. E-selectivity in Wittig reactions of stabilized ylides, and mixed selectivity in reactions of semi-stabilized ylides, was explained by reversible formation of the betaine intermediate or the subsequent OPA intermediate, with kinetically favored cyclization of threo-betaine to trans-OPA or decomposition of trans-OPA to $E$-alkene resulting in the equilibrium between the betaines or OPAs being effectively biased towards the (already thermodynamically favored) threo- 
betaine or trans-OPA. ${ }^{29}$ However, the operation of kinetic control in Li salt-free Wittig reactions of all three ylide types has been demons trated (most significantly for stabilized ylides), ${ }^{26,35}$ and there is no evidence for kinetically preferred decompos ition of threo-betaine or trans-OPA to $E$-alkene, which renders these mechanistic arguments inoperative.

33. Only a handful of Li salt-free Wittig reactions are known to undergo reversible formation of OPA and all such examples are reactions of non-stabilized ylides. The proposal that Wittig reactions (especially of semi-stabilized and stabilized ylides) are generally reversible grew out of the betaine mechanism(see footnote 32), and from the effects exerted by Li cation on the stereoselectivities of the reaction. ${ }^{19,20,21}$ However, even for reactions conducted in the presence of Li salts, the involvement of betaine in the process of OPA formation from ylide and aldehyde is not certain. $\mathrm{Li}^{+}$causes diminis hed $Z$-selectivity in reactions of alkylidenetriphenylphosphoranes, ${ }^{3,14}$ and als o results in altered selectivity in reactions of semi-stabilized ylides compared to $\mathrm{Li}$ salt-free conditions, while little is known regarding the effect of $\mathrm{Li}^{+}$(or other cations) on reactions of stabilized ylides, which are usually formed and purified (and are thus salt-free) prior to the reaction. ${ }^{3}$ Betaine-LiBr complexes have been is olated from reactions of non-stabilized ylides, ${ }^{16,19}$ and there exists one report in which betaine-LiBr complexes have been formed in reactions of a semi-stabilized ylide and undergo Wittig reversal, as judged by positive crossover experiments. ${ }^{22}$ Furthermore, a non-corres pondence between the initial low temperature OPA cis/trans ratio and ultimate alkene Z/E ratio after warming of the OPA (favouring production of the $E$-is omer - "stereochemical drift") has been observed in the reaction of $\mathrm{Ph}_{3} \mathrm{P}=\mathrm{CH}(n-\mathrm{Pr})$ and benzaldehyde in the presence of $\mathrm{LiBr}^{20}$ Positive cros sover experiments indicate that the conversion of cis-OPA into trans-OPA in the examples mentioned above of reactions of alkylidenetriphenylphosphoranes with be nzaldehyde in the presence of $\mathrm{Li}^{+}$involves OPA reversal to ylide and aldehyde. ${ }^{19,25} \mathrm{LiBr}$ has been shown to exert an effect on the stereoselectivity of OPA formation in the reaction of $\mathrm{Ph}_{3} \mathrm{P}=\mathrm{CHCH}_{3}$ and $\mathrm{PhCH}_{2} \mathrm{CH}_{2} \mathrm{CHO}$, but not to affect the stereochemical ratio of the OPA formed from these reactants if added to a pre-formed solution of the OPA to give betaine-LiBr complex. ${ }^{19}$ Also no stereochemical drift was observed in the reaction of $\mathrm{Ph}_{3} \mathrm{P}=\mathrm{CH}(n-\mathrm{Pr})$ with hexanal in the presence of $\mathrm{LiBr}$ in $\mathrm{THF}$. ${ }^{20}$ Thus it appears that OPA formation is irreversible in reactions of aliphatic aldehydes, even in the presence of $\mathrm{Li}^{+}$, and that the diminished Z-selectivity in these reactions arises from the effect of $\mathrm{Li}^{+}$on the initial formation of OPA. Although the direct formation of betaine- $\mathrm{LiBr}$ complex from ylide and aldehyde in the presence of $\mathrm{LiBr}$ is certainly plausible, the pre sence of such complexes in Wittig reaction mixtures does not prove the involvement of betaines (salt-free or as complexes with lithium halide) in the proces s of OPA formation from ylide and aldehyde in the presence of Li salt, since it has been shown that bet aine-LiBr complex can be formed directly from OPA. ${ }^{19}$ Similarly, the fact that reactions of benzaldehyde with non-stabilized ylides in the presence of $\mathrm{Li}^{+}$undergo reversal of OPA to ylide and aldehyde ${ }^{19,25}$ (and that the betaine-LiBr complex produced in the reaction of the semi-stabilized ylide mentioned above undergoes reversal) ${ }^{22}$ does not necessarily mean that betaines are involved on the pathway from OPA to ylide and aldehyde - rather it may occur by direct cycloreversion. It should also be noted that the "Li salt-free" cycloaddition mechanismoperates in reactions conducted the presence of Li salts in solvents that coordinate Li ion strongly (DMSO, DMF), ${ }^{33}$ in reactions with $l o w \mathrm{Li}$ ion concentration in solvents that coordinate Li ion poorly (THF, toluene), ${ }_{14}^{20}$ and in reactions of alkylidenetriphenylphosphoranes with tertiary aldehydes, on which Li salts appear to exert no influence. ${ }^{14}$

34. The observation of cros sover product in $\beta$-hydroxyphosphonium salt ( $\beta$-HPS) deprotonation experiments in alcohol solvent has also led to the suggestion of the operation of reversibility in Wittig reactions in alcohol solvents. ${ }^{27}$ However, it has since been shown that, at least in certain circumstances, the addition of methanol at low temperature (i.e. before OPA decompos ition occurs ) to the Wittig reactions of non-stabilized ylides causes very high $E$-selectivity in the reactions, which in the absence of methanol (or if it is added after warming to room temperature) would show high Z-selectivity. ${ }^{28}$

35. Vedejs, E.; Fleck, T. J. Am. Chem. Soc., 1989, 111, 5861.

36. Reitz, A. B.; Mutter, M.S.; Maryanoff, B. E. J. Am. Chem. Soc. 1984, 106, 1873.

37. Vedejs, E.; Marth, C. F. J. Am. Chem. Soc. 1990,112, 3905.

38. Vedejs E.; Marth, C. F. J. Am. Chem Soc. 1988, 110, 3948.

39. Although the necessity for the formation of oxaphosphetane was recognised by Wittig at the outset (reference 1), he did not consider how exactly it would be formed, nor did he specify whether it would be a true intermediate or a transition state. Subsequently, in the absence of definitive evidence, he settled on the betainemechanis $m$ as being the most plausible: Wittig, G.; Haag, A. Chem. Ber. 1963, 96, 1536.

40. Among the earlier mechanis tic workers, the fact that the [2+2] mechanis ms uperficially contravenes the Woodward-Hofmann rules was a factor in slowing its acceptance/development: S. Trippett, pers onal communication to DGG, 1983.

41. Vedejs, E.; Snoble, K. A. J. J. Am. Chem. Soc. 1973, 95, 5778

42. Vedejs, E.; Fuchs, P. L. J. Am. Chem. Soc. 1973, 95, 822.

43. Vedejs, E; Fleck, T.; Hara, S. J. Org. Chem. 1987, 52, 4637

44. Vedejs, E.; Snoble, K. A. J.; Fuchs, P. L. J. Org. Chem. 1973, 38, 1178.

45. Vedejs, E.; Marth, C. F.; J. Am. Chem. Soc. 1989, 111, 1519.

46. Vedejs, E.; Marth, C. F. Tetrahedron Lett. 1987, 28, 3445.

47. Maryanoff, B. E.; Reitz, A. B.; Graden, D. W.; Almond,H. R. Tetrahedron Lett. 1989, 30, 1361.

48. Schlosser, M.; Schaub, B. J. Am. Chem. Soc. 1982, 104, 5821.

49. Reference 12a.

50. See reference 6e.

51. Bangerter, F.; Karpf, M.; Meier, L. A.; Rys, P.; Skrabal, P.; J. Am. Chem. Soc. 1998, 120, 10653. 
52. Ward, W. J.; McEwen, W.E. J. Org. Chem. 1990, 55, 493.

53. Frøyen, P. Acta. Chem. Scand. 1972, 26, 2163.

54. Blade-Font, A.; Vanderwerf, C. A.; McEwen, W. E. J. Am. Chem. Soc. 1960, 82, 2396.

55. The rate of OPA decomposition equals the rate of alkene formation in reactions of non-stabilized ylides, ${ }^{24,25,51}$ and the diastereomeric ratios of the OPA and alkene are identical in these reactions and in those of semi-stabilized ylides in which OPAs can be observed spectroscopically. ${ }^{23,24,25,26,35,46,50,51}$ In experiments involving generation of OPA by means independent of a Wittig reaction (via transient betaine species) from precursors of defined stereochemistry (e.g. $\beta$-HPS, epoxide), the stereochemistry of the precurs or is retained in the alkene product after OPA decomposition. This has been observed in experiments involving OPAs derived fromnon-stabilized,,$^{23,24,25,26,41,42,46,51}$ semi-stabilized ${ }^{35,42,52}$ and stabilized ylides. ${ }^{35}$ In a particular Wittig reaction of a $P$-stereogenic semi-stabilized phosphonium ylide, the stereochemistry at phosphorus was retained in the phosphine oxide. ${ }^{54}$ All of this evidence is consistent with the operation of a syn-elimination of phosphine oxide from a cyclic intermediate with trigonal bipyramidal phosphorus.

56. Non-stabilized ylides of the general structure $R^{a} R^{b} R^{c} P=C H R^{1}$, where $R^{1}=$ alkyl and the phos phonium $R^{a} R^{b} R^{c} P$ moiety is not $\mathrm{Ar}_{3} \mathrm{P}$ or $t$-BuAr$r_{2} \mathrm{P}$, show much lower kinetic selectivity for cis-OPA. ${ }^{14,25,26}$ This can be rationalized as being a cons equence of decreased 1-3 interactions and thus a lower propensity towards TS puckering. The lower Z-selectivity generally observed in reactions of alkylidenetrialkylphosphoranes (see reference 14) is not only a consequence of the lower kinetic selectivity for cis-OPA mentioned here. The cis-OPA reverts to ylide and aldehyde while the trans-OPA does not, and thus the trans-OPA accumulates. See references 13,25 , and 26.

57. The trans-selective TS was initially proposed to be planar, which would be consis tent with the observed high $E$-s electivity. ${ }^{35}$

58. For example, a negatively puckered cis-selective TS with a favorable relative orientation of reactant dipoles (Fig. 1(b) with aldehyde $H$ and $R^{1}$ swapped) suffers from strong 1-3 (as well as significant 1-2) interactions, while one with the opposite sense of puckering (Fig. 1(d)) has an electrostatically dis favored disposition of reactant dipoles. A planar cis-selective TS (Fig. 1(c)) should not be particularly disfavored electrostatically, but suffers fromlarge 1-2 interactions and lacks the electrostatically favored anti-parallel orientation of reactant dipoles that is present in the TS of Fig. 1(b). Thus high $E$-selectivity is observed in general in Wittig reactions of stabilized ylides in non-polar or polar-aprotic media, with selectivity being extremely high for ylides in which phos phorus bears bulky substituents (e.g. triphenylphosphine-derived ylides), as the possibility of large 1-3 interactions dictates that these discriminate particularly well against puckering of the cis-selective TS. If the phosphorus substituents are not sobulky (e.g. if one phenyl is replaced by methyl), then a different cis-selective TS with an antiparallel orientation of reactant dipoles can be envis ag ed (Fig. 1(b) with the positions of $\mathrm{R}^{1}$ and $\mathrm{H}$ s wapped) since placement of the large substituent in the pseudo-axial position is not discriminated against to the same extent by 1-3 interactions, consistent with the lower $E$-selectivity observed (see reference 14 ).

59. Diminished $E$-selectivity, and even predominant $Z$-selectivity has been observed in reactions of stabilized ylides in methanol (see references 2,14, and 35). It seems likely that this results froma solvent-induced decrease in the importance of the interaction of reactant dipoles in the cycloaddition TSs. In this scenario, the factors governing TS geometry may be quite similar to those in reactions of semi-stabilized ylides.

60. It is still common for modern undergraduate texts to state that one or other of OPA or betaine is the first formed intermediate, but then qualify this by saying that some or all Wittig reactions may react by the other intermediate under certain circu mstances. For example see: McMurry, J. Organic Chemistry, $8^{\text {th }}$ edition; Brooks/Cole; 2011, p. 747; Carey, F. A. Organic Chemistry, $7^{\text {th }}$ Edition; McGraw-Hill: New York; 2008, pp. 729-730; Wade Jr., L.G. Organic Chemistry, $7^{\text {th }}$ edition; PrenticeHall: New Jersey; 2010, p. 836. See also references 29 and 30.

61. Some texts still retain the betaine mechanismas the only explanation of the Wittig reaction mechanism: e.g. Vollhardt, K. P. C.; Schore, N. E. Organic Chemistry: Structure \& Function 6th edition; Freeman: 2011, pp. 806-807.

62. Some texts do definitively show OPA as the first-formed intermediate in the Wittig reaction: Bruice, P. Y. Organic Chemistry 6th edition; Prentice-Hall: New Jersey; 2011, pp. 805-806; Smith, J. G. Organic Chemistry 2nd edition; McGraw-Hill: New York; 2008, pp. 794-795. However, even these do not tackle the source of stereoselectivity in the reaction.

63. OPAs derived fromsemi-stabilized ylides containing the dibenzophosphole moiety have been observed by low te mperature NMR. For these, stereospecific conversion to alkene has been demonstrated by the same method as was used for reactions of non-stabilized ylides. ${ }^{35}$

64. Harcken, C.; Martin, S. F. Org. Lett. 2001, 3, 3591.

65. Cotter, J.; Hogan, A-M. L.; O’Shea, D. F. Org. Lett. 2007, 9, 1493-1496.

66. Dunne, E. C.; Coyne, E. J.; Crowley, P. B.; Gilheany, D. G. ; Tetrahedron Lett. 2002, 43, 2449

67. This can be synthetically convenient, for example, it may have contributed to the results of recent microwave accelerated reactions: See reference $7 \mathrm{c}$.

68. The $Z / E$ ratio initially determined from analysis of the ${ }^{1} \mathrm{H}$ NMR of the crude product from the synthesis of $4-(2$ 'bromophenyl)but-3-en-2-one of 40:60 was observed to have changed to 0:100 after six months upon obtaining a ${ }^{1} \mathrm{H}$ NMR of the same crude sample.

69. Byrne P. A.; Rajendran, K. V.; Muldoon, J.; Gilheany, D. G. Org. Biomol. Chem. 2012, 10, 3531.

70. For example, although 2,2'-difluorostilbene can be obtained with very high Z-selectivity $(Z / E=94: 6)$ in the reaction of 2fluorobenzylidene-triphenylphosphorane and 2-fluorobenzaldehyde (see reference 69), it is excluded from this study due 60 the propensity of the $Z$-is omer to undergo is omeris ation - see reference 66. 
71. For example: (i) the non-is omeris ation of many of the other stilbenes in contact with alumina was demonstrated by subjecting samples of purified stilbene heavily enriched in the $Z$-isomer (or in some cases containing only the $Z$-is omer) to the typical chromatographic conditions used to purify the stilbenes - i.e. elution through neutral alumina using cyclohexane or pentane as solvent. In all cases the stilbene $Z / E$ ratio was unchanged after being chromatographed; (ii) for reactions of ester-stabilized ylides, experiments were carried out to show that the $Z$-is omer of the enoate product did not is omerise under the reaction conditions. See the supplementary information for further details of these control experiments.

72. See reference $28 b$.

73. OPA cis/trans ratio determined from the erythro/threo ratio of the $\beta$-HPS produced in the low temperature acid quenching of the Wittig reaction.

74. OPA cis/trans ratio determined by low temperature ${ }^{31} \mathrm{PNMR}$ of the Wittig reaction mixture.

75. (a) McEwen, W. E.; James, A. B.; Knapczyk, J. W.; Killingstad V. L.; Shiau, W. -I.; Shore, S.; Smith, J. H. J. Am. Chem. Soc. 1978, 100, 7304; (b) McEwen, W. E.; Fountaine, J. E.; Schulz, D. N.; Shiau, W. I. J. Org. Chem. 1976, 41,1684; (c) McEwen, W.E.; Shiau, W. I.; Yeh, Y. I.; Schulz, D. N.; Pagilagan, R. U.; Levy, J. B.; Symmes, C.; Nels on, G. 0.; Granoth, I. J. Am. Chem. Soc. 1975, 97, 1787; (d) McEwen, W. E.; Kyllingstad, V. L.; Schulz, D. N., Yeh, Y. I. Phosphorus $1981,1,145$.

76. Keldsen, G. L.; McEwen, W.E. J. Am. Chem. Soc. 1978, 100, 7312.

77. McEwen, W.E.; Cooney, J. V. J. Org. Chem. 1983, 48, 983.

78. Zhang, X.; Schlosser, M. Tetrahedron Lett. 1993,34, 1925.

79. Yamataka H.; Nagareda K.; Ando, K.; Hanafusa, T. J. Org. Chem. 1992, 57, 2865.

80. Cushman, M.; Nagarathnam, D.; Gopal, D.; Chakraborti, A. K.; Lin, C. M.; Hamel, E. J. J. Med. Chem. 1991, 34, $2579-2588$.

81. (a) Harrowven D. C.; Guy I. L.; Howell, M.; Packham, G.; Synlett 2006, 2977; (b) Harrowven, D. C.; Guy, I. L.; Nanson, L.; Angew. Chem. Int. Ed. 2006, 45, 2242.

82. Takenaka, N.; Sarangthem, R. S.; Captain, B. Angew. Chem. Int. Ed. 2008, 47, 9708-9710.

83. Schlosser, M.; Schaub, B.; de Oliveira-Neto, J.; Jegenathan, S. Chimia, 1986,40, 244.

84. Reference 14, pp 61-70.

85. The reaction of benzylidenemethyldiphenylphosphorane 3a with benzaldehyde favours $E$-selectivity to a much greater extent than the corres ponding reaction of benzyildenetriphenylphosphorane $\mathbf{4 a}$, and hence the greater shift towards $Z$-selectivity in reactions of the former with ortho-heteroatomsubstituted benzaldehydes represents a much larger decrease in the activation energy of the cis-selective pathway in these reactions.

86. KHMDS was used to generate the ylide from the precurs or phosphoniumsalt.

87. Byrne, P. A.; Müller-Bunz, H.; Gilheany, D. G. manuscript in preparation.

88. See reference 2, page 882-887, in which can be found an extensive collection of examples of atypical Wittig reaction stereoselectivity apparently induced by the presence of a suitably placed heteroatomon the aldehyde reactant. Amongst these are included numerous examples of high $Z$-selectivity in reactions of $\beta$-alkoxy aldehydes. The vast majority of these examples were carried out in polar protic solvents - most commonly methanol. The same section of reference 2 als o includes examples of high $Z$-selectivity in reactions of $\alpha$-heteroatomsubstituted aldehydes. Aldehyde $\mathbf{6 5}$ is, in addition to being a $\beta$-heteroatom subs tituted aldehyde, als o a heteroatom $\alpha$ to the carbonyl, which may have some impact on the level of $Z$-selectivity observed with this aldehyde.

89. Tronchet, J. M.J.; Gentile, B.; Helv. Chim. Acta, 1979, 62, 2091.

90. Valverde, S.; Martin-Lomas, M.; Herradon, B.; Garcia Ochoa, S.; Tetrahedron, 1987, 43, 1987.

91. Suzuki, M.; Doi, H.; Kato, K.; Björkman, M.; Långström, B.; Watanabe, Y.; Noyori, R.; Tetrahedron, $2000,56,8263$.

92. Jarosz, S.; Skóra, S.; Szewczyk, K.; Tetrahedron:Asymmetry, 2000, 11, 1997.

93. Suzuki, M.; Kato, K.; Watanabe, Y.; Satoh, T.; Matsumura, K.; Watanabe, Y.; Noyori, R.; Chem. Comm. $1999,307$.

94. Krueger, E. B.; Hopkins, T. P.; Keaney, M. T.; Walter, M. A.; Boldi, A. M. J. Comb. Chem. 2002, 4, 229.

95. The reaction of semi-stabilised ylide benzy lidenetripheny lphosphorane (4a) with a variant of aldehyde $\mathbf{6 5}$ (with a benzy loxy group in place of the methoxy group) in THF is reported on pg. 886 of reference 2 to give a Z/E ratio of 95:5.

96. This ylide was chosen as a test substrate for the reaction with $\mathbf{6 5}$ due to its low intrinsic kinetic $Z$-selectivity in reactions with aliphatic aldehydes lacking a $\beta$-heteroatom substituent (see Table 6 entry 9).

97. Hannesian, S.; Huang, G.; Chenel, C.; Machaalani, R.; Loiseleur, O.; J. Org. Chem. 2005, 70, 6721.

98. Related $P$-methyldibenzophosphole-derived semi-stabilised ylides have previously been reported to show exceptionally high $E$-selectivity in reactions with cyclohexanecarboxaldehyde - see reference 46.

99. McEwen, W.E. ; Smith, J. H.; Woo, E. J. J. Am. Chem. Soc. 1980, 102, 2746.

100. Cairns, S. M.; McEwen, W.E. J. Org. Chem. 1987, 52, 4829.

101. Nakanis hi, W.; Hayashi, S.; J. Org. Chem. 2002, 67, 38.

102. Yamane, K.; Hayashi, S.; Nakanishi, W.; Sasamori, T.; Tokitoh, N. Polyhedron 2008, 27, 3557.

103. Hayashi, S.; Yamane, K.; Nakanishi, W.J. Org. Chem. 2007, 72, 7587.

104. Kilian, P.; Slawin, A. M. Z.; Woollins, J. D. Phosphorus, Sulfur Silicon Relat. Elem. 2004, 179, 999.

105. Reiter, S. A.; Nogai, S. D.; Karaghios off, K.; Schmidbaur, H. J. Am. Chem. Soc. 2004, 126, 15833.

106. Owsianik, K.; Chauvin, R.; Balińska, A.; Wieczorek, M.; Mikołajczyk, M. Organometallics 2009, $28,4929$.

107. Zahn, S.; Frank, R.; Hey-Hawkins, E.; Kirchner, B. Chem Eur. J. 2011, 17, 6034. 
108. Hierso, J.-C.; Fihri, A.; Ivanov, V. V.; Hanquet, B.; Pirio, N.; Donnadieu, B. ; Rebière, B. ; Amardeil, R. ; Meunier, P. J. Am. Chem. Soc. 2004, 126, 11077.

109. Bonnafoux, L.; Ernst, L.; Leroux, F. R.; Colobert, F. E. J. Org. Chem. 2011, 3387.

110. Maji, P.; Krishnamurthy, S. S.; Nethaji, M. New J. Chem. 2010, 34, 1478.

111. Mó,O.; Yáñez, M.; Eckert-Maksić, M.; Maksić,Z. B.; Alkorta, I.; Elguero, J. J. Phys. Chem. A. 2005, $109,4359$.

112. Kawashima, T. Watanabe, K.; Okazaki, R. Tetrahedron Lett. 1997, 38, 551.

113. Matsukawa, S.; Kojima, S.; Kajiyama, K.; Yamamoto, Y.; Akiba, K.-y.; Re, S.; Nagase, S. J. Am. Chem. Soc. 2002, 124, 13154. 